Atmos. Chem. Phys., 13, 4111-4131, 2013

www.atmos-chem-phys.net/13/4111/2013/

doi:10.5194/acp-13-4111-2013

(c) Author(s) 2013. CC Attribution 3.0 License.

\title{
Phenomenology of convection-parameterization closure
}

\author{
J.-I. Yano ${ }^{1}$, M. Bister ${ }^{2,}$, Ž. Fuchs ${ }^{3}$, L. Gerard ${ }^{4}$, V. T. J. Phillips ${ }^{5}$, S. Barkidija ${ }^{3}$, and J.-M. Piriou ${ }^{1}$ \\ ${ }^{1}$ GAME/CNRS, UMR3589, CNRS-INSU-Météo France, Toulouse, France \\ ${ }^{2}$ Department of Physics, University of Helsinki, Helsinki, Finland \\ ${ }^{3}$ Physics Department, Faculty of Science, University of Split, Split, Croatia \\ ${ }^{4}$ Royal Meteorological Institute of Belgium (Dept R\&D), Brussels, Belgium \\ ${ }^{5}$ School of Earth and Environment, University of Leeds, Leeds, UK \\ *For contribution to Sect. 2.
}

Correspondence to: J.-I. Yano (jun-ichi.yano@zmaw.de)

Received: 15 June 2012 - Published in Atmos. Chem. Phys. Discuss.: 28 September 2012

Revised: 14 March 2013 - Accepted: 20 March 2013 - Published: 18 April 2013

\begin{abstract}
Closure is a problem of defining the convective intensity in a given parameterization. In spite of many years of efforts and progress, it is still considered an overall unresolved problem. The present article reviews this problem from phenomenological perspectives.

The physical variables that may contribute in defining the convective intensity are listed, and their statistical significances identified by observational data analyses are reviewed. A possibility is discussed for identifying a correct closure hypothesis by performing a linear stability analysis of tropical convectively coupled waves with various different closure hypotheses. Various individual theoretical issues are considered from various different perspectives. The review also emphasizes that the dominant physical factors controlling convection differ between the tropics and extra-tropics, as well as between oceanic and land areas.

Both observational as well as theoretical analyses, often focused on the tropics, do not necessarily lead to conclusions consistent with our operational experiences focused on midlatitudes. Though we emphasize the importance of the interplays between these observational, theoretical and operational perspectives, we also face challenges for establishing a solid research framework that is universally applicable. An energy cycle framework is suggested as such a candidate.
\end{abstract}

\section{Introduction}

The importance of convection parameterization both in numerical weather forecasts as well as climate projections can hardly be overemphasized. There are various fundamental issues to be addressed in order to make it more robust.

In general, convection parameterization can be considered as consisting of the two major parts: (1) regulation of the amount of convection by large-scale (grid-scale) variables and (2) regulation of the large-scale variables by convection. These two problems are usually called closure and the cloud model, respectively. Putting it differently, convective closure is a problem of finding a relation of the intensity of the subgrid-scale convective activity to large-scale variabilities (model-resolved variables). As emphasized by Arakawa and Schubert (1974), "The real conceptual difficulty in parameterizing cumulus convection starts from this point". Although extensive progress has been made since that time (e.g., Arakawa and Chen, 1986; Xu, 1994), the statement is still valid even today (cf. Arakawa, 2004; Yano et al., 2005a). The problem may furthermore include the issues of conditions for triggering and suppression of convection under a given scheme. Here triggering and suppression, respectively, refer to technical conditions for turning on and off a given convection parameterization ${ }^{1}$.

\footnotetext{
${ }^{1}$ As will be emphasized in Sect. 5.5, the current convection parameterizations deal only with ensemble effects of convection; thus, trigger here more specifically refers to "onset" of an ensemble of convection as a whole. From a strictly theoretical point of view, especially when a parameterization is based on a quasi-equilibrium
} 
Under the mass-flux formulation (Arakawa and Schubert, 1974), the closure problem can be more formally stated in the following manner. A core of the mass flux formulation resides in the quantity called, mass flux, $M$. Once the mass flux at cloud base is defined, the convective mass flux through the remainder of the atmosphere is computed using the chosen cloud model. From the resulting mass-flux profile, more or less all of the convective tendencies required for a large-scale model can then be obtained with certain caveats to be referred to Donner (1993), and Yano and Plant (2012b). Here, the mass flux, $M$, is defined as an upward momentum flux associated with convection averaged over a given horizontal area. The area in mind, which is expected to correspond to the grid box size, is traditionally taken to be much larger than individual clouds (i.e., scale separation principle). However, as the resolution of the model increases, this assumption also begins to break down.

As a standard procedure, the mass flux, $M$, is divided into the two components, a normalized vertical profile, $\eta(z)$, and a time-dependent amplitude, $M_{\mathrm{B}}(t)$ :

$M=\eta(z) M_{\mathrm{B}}(t)$.

Here, the convective amplitude (or convective intensity), $M_{\mathrm{B}}$, is usually defined as the mass flux at the convection base. The convective vertical profile, $\eta$, is defined by a "cloud model" 2 , which usually constitutes a specification of entrainment and detrainment, or mixing rate of convection with the environment (cf. de Rooy et al., 2013). The closure in turn defines the convective amplitude, or convective intensity, $M_{\mathrm{B}}$. This is the main concern of the present review.

The present paper reviews the closure problem from phenomenological perspectives, rather than as being a formulational issue. Typically, a closure is based on a steady-state budget of a certain physical variable that is expected to control the convective evolution. Thus, the key physical question in the present review is this: what controls convection?

The present review essentially hovers around this key question. In the course of examining this question, the paper considers the issues of both onset and intensity of convection as a single set of questions, rather than as two separate ones because a process or a physical variable that defines onset of convection would also naturally contribute in defining the intensity of convection. For example, if a positive CAPE (con-

hypothesis (cf. Yano and Plant, 2012a), it is highly questionable whether such onset ever happens. An energy cycle analysis by Yano and Plant (2012b) suggests otherwise: ensemble convection can repeat a cycle of discharge and recharge without ever being triggered and suppressed (i.e., being switched on and off). Individual convective elements may well be "triggered". However, this concept should never be confused with this technical issue of "trigger" in convection parameterization. This is a key issue to be discussed in Sect. 5.5. Readers are also encouraged to refer to Yano (2011).

${ }^{2}$ It would be important to realize that the cloud model only concerns a vertical profile, $\eta(z)$, of convection, and not at all its time evolution. In a nutshell, this is the steady-plume hypothesis. vective available potential energy, $\mathrm{cf}$. Sect. 3.1,2) defines onset of convection, its magnitude would equally contribute in defining the convective intensity. By taking this perspective, we do not consider the issue of trigger (as well as suppression) as a separate issue from a general closure problem either. In spite of critical importance for defining trigger and suppression in operational implementations, we believe that this restriction is legitimate in the present review by focusing on "phenomenological" aspects of the closure problem. In considering the problem from those perspectives, as it turns out, it is still hard to answer a simpler version of the following question: what controls convection ${ }^{3}$ ?

Many other related issues are not discussed either. For example, in the original mass-flux formulation by Arakawa and Schubert (1974), a simple entraining plume is adopted as a cloud model. To be realistic, the cloud model should also handle various additional elements, including downdrafts. In practice, it is not possible to consider the closure problem of specifying the convective intensity, or more specifically cloud-base convective updraft mass flux, without specifying a cloud model, because the behavior of a parameterization would simply be changed by a choice of the latter even under a same closure. For example, if the cloud model does not give the sensitivity to moisture by entrainment and does not contain an unsaturated downdraft, then the closure has to compensate for the crudeness of the cloud model. Note that the downdraft provides a further process for drying and cooling the boundary layer in addition to the convective updraft. Thus, broadly speaking, the absence of the former must be compensated by increasing the convective updraft in the closure.

In order to set a scene, the present paper begins by providing global and regional perspectives for atmospheric convection in next section (Sect. 2). It may be argued that the first step for constructing a closure is to identify a variable (or a set of them) that controls convection observationally (Sect. 3). Section 3.1 lists such potential control variables for convection, then Sect. 3.2 reviews such data analysis.

Section 4 examines the closure problem from a perspective of the tropical large-scale dynamics. Various types of largescale convective variabilities (so-called convectively coupled waves) over the tropics may be understood in terms of coupling between convection and large-scale dynamics. Under these theories, a right closure must be chosen in order to explain these variabilities properly. Conversely, the consistency of a theory with observations provides an ample test for an adopted closure for a theory. Thus, a review of tropical wave

\footnotetext{
${ }^{3}$ A major exception is Sect. 5.5, where the role of CIN (convective inhibition, cf. Sect. 3.1, 2c) in triggering individual convective plumes is discussed. However, the issue of "trigger" therein has nothing to do with the "trigger" in standard mass-flux parameterization, as the discussion in this subsection attempts to make it clear. A full discussion of this issue is found in Yano (2011).
} 
theories provides good general insights on the closure problem.

Section 5 in turn examines the individual closure hypotheses from theoretical perspectives by focusing on individual physical processes in concern. This section intends to provide a good contrast with general discussions in the precedent two sections. Issues of the closure in the high-resolution limit is specifically discussed in Sect. 5.7. The paper is concluded in Sect. 6.

\section{Global and regional perspectives}

We begin the present section by introducing a definition of convection: "thermally direct circulations which result from the action of gravity upon an unstable vertical distribution of mass, with vertical taken to mean along the gravitational vector" (Emanuel, 1994). We usually call this "action of gravity upon an unstable vertical distribution of mass" buoyancy, and we take this terminology into the following. Based on this definition, we basically take a point of view that convection is a dynamical process driven by buoyancy. Thus, ultimately, convection would be best described in terms of an energy cycle (cf., Sect. 5.6). However, unfortunately, not all the materials presented in the following based on available observations and theories fit into this general picture. The present section also attempts a partial explanation as to why.

First of all, what role does convection play in atmospheric circulations? We pose this question as a way of introducing the closure problem of convection parameterization both from global and regional perspectives. We first consider the role of moist convection from a perspective of global heat budget in the first subsection. The next subsection in turn discusses regional differences of atmospheric convection. Section 2.2 also provides a preview for the whole discussions in the subsequent part of the paper.

\subsection{Moist convection in global perspectives}

Climatological energy balance of the globe (Newell et al., 1974) shows that latent heat release is needed in opposing the radiative cooling. Even though there is transfer of heat from lower to higher latitudes by the atmosphere and oceans, the effect of condensation (and freezing/deposition) is still crucial in balancing the heat loss by radiation in the free troposphere over most of the globe. This does not mean that in order to maintain climatological energy balance, condensation itself should occur everywhere. Atmospheric convection is often very localized, especially in the tropics. The adiabatic heating associated with compensating subsidence can locally balance with radiative cooling without invoking local latent heating. Excess latent heating associated with local convection would be balanced with adiabatic cooling associated with convective ascent. Gravity waves are expected to redistribute the convectively generated heat anomalies hor- izontally on fast time scales. However, gravity waves can propagate straight only up to the scale of the Rossby deformation radius and, in general, less when dissipation is accounted for. As a result, the dispersion of heating depends on the latitude: the Rossby deformation radius is about $1200 \mathrm{~km}$ at $15^{\circ} \mathrm{N}$ and $400 \mathrm{~km}$ at $50^{\circ} \mathrm{N}$, using values from Bretherton et al. (2005).

The importance of latent heating can be understood if one considers that, for example, over the tropics, CAPE (convective available potential energy) would increase by about $700 \mathrm{~J} \mathrm{~kg}^{-1}$ every day if radiative cooling (assumed to be $1.4 \mathrm{~K} \mathrm{day}^{-1}$ from 900 to $150 \mathrm{hPa}$ ) were not compensated for by latent heating (cf. Emanuel et al., 1994). In order to prevent steady increase of CAPE, which is not observed, moist convection must consume CAPE in compensation. A basic state of the free troposphere and the boundary layer must be, in turn, such that a rather small change can easily trigger moist convection frequently enough. Even in the middle latitudes, outside of the regions of forced ascent associated with baroclinic waves or topography, deep convection is needed in causing latent heating. A major exception to this rule is high-latitude regions in the free troposphere of the summer hemisphere where the total radiative heating can be even positive.

\subsection{Difference over globe: tropics and midlatitudes}

Discussions in the main part of the review will be based on a premise that a certain closure hypothesis is universally valid globally. This premise is necessary in order to develop a numerical model that is valid globally. Though some issues arise from regional differences, they are rather treated as side issues in the following for this reason. In order to counterbalance this "universal" view, the present subsection summarizes some of the differences over the globe.

As will be stressed in Sect. 4, the temperature does not vary much horizontally (weak temperature gradient: Sobel et al., 2001) in the tropics. However, the situation is very different in the midlatitudes, where the temperature variations are much larger. As a result, the effect of lower tropospheric moisture is more important in the tropics in a relative sense. If, however, we are interested in forecasting thunderstorms and mesoscale convective systems in midlatitudes, where the temperature has a large contribution to the variation of CAPE, it may not be a good idea to use a moisture convergence closure.

It will be stressed in Sect. 3.2 that precipitation in the tropics is highly correlated with lower tropospheric water vapor (or saturation fraction, Sect. 3.1,8a). This makes sense even from a point of view of convective energy cycle as will be discussed in Sect. 5.6 because low- to midtropospheric moisture has much to do with buoyancy of moist rising parcels (especially when the temperature variations are small) and also greatly affects the downdrafts. 
CAPE will be one of the key variables discussed in the following sections. However, Fuchs and Raymond (2002), Donner and Phillips (2003), and Fuchs (2007) provide evidence that the CAPE closure may not work well in the tropics. As will be discussed in Sect. 5.7, in midlatitude mesoscale forecasts, on the other hand, the CAPE closure works rather well - if it is used properly. From one of the authors' experience, for example, a scheme by Bechtold et al. (2001) based on a CAPE closure works well in the midlatitudes. Donner and Phillips (2003), in turn, find that convective quasiequilibrium (steadiness of the CAPE budget) is a poor approximation at subdiurnal timescales in midcontinent North America (cf., Sect. 5.4).

Convective instability, which may be crudely measured by CAPE (but see Sect. 5.6), is controlled by three major factors: (1) the boundary moist entropy, (2) free tropospheric temperature, and (3) moisture in the low-to-middle troposphere (LTMT). Which factor dominates in what situation? Here, we may hypothesize that the main limiting factor of convective intensity is the one that represents the largest temporal and spatial variation. Based on the dominance among these factors, we can divide the globe into three major regimes: (i) tropical oceans, and land areas in the (ii) absence or (iii) presence of large free-tropospheric temperature variations. Let us consider these regimes one by one.

i. Over tropical oceans, free-tropospheric temperature variations are small due to large Rossby deformation radius. Also, the diurnal variation of boundary layer entropy is relatively small. However, the low-to-middle troposphere (LTMT) moisture can vary significantly over various scales. As a result, the variations of undiluted CAPE are small, and consequently the LTMT moisture becomes the limiting factor for convection. This is consistent with many studies showing the relation of LTMT moisture, or column water vapor, with convection as will be discussed in Sect. 3.2.

ii. Land areas without large free-tropospheric temperature variations can be found in the tropics or sometimes also in the middle to higher latitudes. Over the land areas, there is typically a large-amplitude diurnal cycle in boundary layer variabilities. The LTMT moisture can also vary. For this reason, Zhang (2002) and Donner and Phillips (2003) note that quasi-equilibrium is not valid to model diurnal cycles of convection, and the net rate of change of CAPE can be comparable to changes of the boundary-layer air, as will be discussed in Sect. 5.4.

Here, a careful specification of the entrainment rate is important, for example in transformation of shallow convection into deep convection (cf. de Rooy et al., 2013). Derbyshire et al. $(2004,2011)$ suggest that lowto-middle level moisture and the size of thermals controls the buoyancy, depth and rate of ascent, and entrainment rate under the transformation process. More specifically, a dry LTMT affects the strength and depth of the downdrafts and the value of $\theta_{\mathrm{e}}$ in the downdrafts. Furthermore, entrainment and upward growth of convection may depend on LTMT. Finally, downdrafts may enhance the development of big thermals and deep clouds (cf. Khairoutdinov and Randall, 2006).

It is likely that convection occurs when/where the boundary layer entropy reaches its maximum during the diurnal cycle due to convection. (Recall that heating occurs also outside of convection due to subsidence. Therefore, convection itself is likely to occur in preferred places and times only.) However, convection can be enhanced when the LTMT moisture is large. Hence, over these land areas the moisture can play an important role in defining a location of convection. The timing of convection might still follow the diurnal cycle. James and Markowski (2010) note by studying convection with a cloud resolving model that the influence of dry air on convection was sensitive to the value of CAPE. The detrimental effect of dry air by entrainment on convective intensity was much greater with a lower value of CAPE. So this regime, namely land areas without large free-tropospheric temperature anomalies, resembles the first regime (tropical oceans), but it differs by a prominent presence of a diurnal cycle.

iii. The third regime is land areas with large freetropospheric variation of temperature. Therefore, also CAPE, or lapse-rate, variations can be large. James and Markowski (2010) noted that when CAPE is large then dryness of the environment is relatively inconsequential for the vigor of convection. Wu et al. (2009) showed that with more stable air, the moisture became relatively more important for the transition to deep convection. Conversely, with the drier environment, stability became relatively more important for the transition to deep convection (cf. their Fig. 6a).

Zhang and Klein (2010) studied the mechanisms affecting the transition to deep convection in the Southern Great Plains ARM site. They noted that the lower (free-)tropospheric lapse rate was related to subsequent amount of total precipitation and maximum rain rate. CAPE, however, did not seem to be important. High relative humidity above the boundary layer $(2-4 \mathrm{~km})$ is identified as a better indicator for an earlier onset of convective precipitation (cf. their Fig. 9).

It is intriguing as to why in some cases CAPE seems to be important and in other cases the lower tropospheric lapse rate (or its contribution to CAPE) is important. In this respect, the recent study of Raymond and Herman (2011) is suggestive: they show that the temperature variations in the upper troposphere are not eliminated as fast as those in the lower troposphere. Their experiment suggests that the upper troposphere is less constrained 
by convective quasi-equilibrium than the lower troposphere $^{4}$.

CAPE, however, is dominated by upper tropospheric contributions (cf. Sect. 5.4). If the difference of the temperature between the air parcel and its environment is constant with height, the contribution to CAPE from the layer between 300 and $100 \mathrm{hPa}$ is as large as a contribution from the layer between 900 and $300 \mathrm{hPa}$. In the cases where the lower tropospheric buoyancy (and/or CIN) is important for convection, CAPE may not have much predictive value.

An implication from Raymond and Herman (2011) is that it may be useful to limit a range of vertical integral for CAPE to the lower troposphere, which may provide a more practically useful measure of convective instabilities. The result more generally suggests the importance of considering different instability measures for convection of different vertical scales, as explicitly taken into account in the cloud work function and PEC (cf. Sect. 5.6).

Regarding the three suggested regimes for convection, the study by Stone and Carlson (1979) is revealing. Above the boundary layer, zonal mean lapse rates were observed to be within $20 \%$ of the moist adiabatic lapse rate from the Equator up to about $30^{\circ} \mathrm{N}$ in January and $50^{\circ} \mathrm{N}$ in July and appreciably more stable in higher latitudes. This is due to moist convection being more important at lower latitudes and baroclinic eddies at higher latitudes when it comes to the average effect on the lapse rate.

\section{Observational perspectives}

A list of variables potentially contributing to control of convection is presented in the first subsection. We may argue that from an observational perspective, the closure problem reduces to that of identifying a nonlinear function of these control variables that defines convective intensity. Existing data analyses are reviewed in the second subsection from this perspective.

\footnotetext{
${ }^{4}$ However, note more precisely that their experiment examines a response of a convective system to a sudden change of the environmental profile, over a convective-scale model time step $(0.5 \mathrm{~s}$ in their case). We should realize that this setting has little direct relevance to the closure problem, which seeks to define a convective intensity against a slowly varying large-scale state. The study does not say much about convective quasi-equilibrium (CQE), as originally proposed by Arakawa and Schubert (1974) either. The latter, again, only concerns a situation under a slowly varying large-scale state. Raymond and Herman's argument is based on a reinterpretation of CQE as an adjustment process. See Sect. 4.5 of Yano and Plant (2012a) for in-depth discussions on this reinterpretation.
}

\subsection{List of variables and physical basis}

Atmospheric moist convection is locally controlled by various physical processes and associated physical variables. Here, these variables are listed in the order of stability measures, and thermodynamic and dynamic variables. Note that all those variables can be evaluated from observations if necessary basic variables are properly measured. In this very respect, all of them reflect certain corresponding physical processes, though some of them are more often employed in data analysis, while others are more often employed in modeling contexts, mostly due to historical as well as practical reasons. For this reason, the following list is constructed without discriminating between those two major categories.

1. The vertical temperature gradient: the simplest stability measure in analogy with dry convective instabilities (cf. Stone and Carlson, 1979; Zhang and Klein, 2010).

2. CAPE (convective available potential energy): by definition, convection is driven by buoyancy; thus, it is natural to expect that the convective intensity is controlled by the strength of buoyancy acting on a convective flow. The easiest way to measure the strength of buoyancy forcing on convective flows is to take a simple liftingparcel argument, which leads to a definition of CAPE. There are various ways for lifting an air particle from the surface (or a middle of boundary layer), leading to various different definitions for CAPE.

2a. Undiluted CAPE: the simplest, and the standard procedure for diagnosing CAPE from sounding is to lift an air particle from the surface without any mixing with the environment.

2b. Diluted CAPE: a more "realistic" estimate can be made by mixing the air particle with the environment at a certain rate. An updated version of the Kain-Fritsch scheme (Kain, 2004) takes it for closure.

2c. CIN (Convective INhibition): it is defined by a vertical integral of negative part of parcel-lifted buoyancy (cf. Sect. 5.5). Raymond et al. (2003) propose DCIN (Deep Convective INhibition) as a similar measure of inhibition focusing on deep convection.

3. Cloud work function (Arakawa and Schubert, 1974): it is work performed by convective buoyancy per convective mass flux defined at the convection base. It is equal to a vertical integral of vertical buoyancy flux normalized by a convection-base convective vertical momentum (mass flux). The cloud work function provides a more accurate estimate than CAPE for an efficiency of convective kinetic energy generation by buoyancy forcing (cf. Sect. 5.6).

3a. PEC (potential energy convertibility): the cloud work function can be estimated both from cloud-resolving 
models and large-eddy simulations by replacing the convection-base mass flux by an alternative normalization factor for the convective vertical momentum, as proposed by Yano et al. (2005b).

4. GCAPE (generalized convective available potential energy: Randall and Wang, 1992): this is defined as part of the available potential energy (APE) calculated for the moist atmosphere. APE is defined as the difference between the total enthalpy of the given atmospheric state and that of the reference state (Lorenz, 1978, 1979). Generally, the reference, defined as the minimum enthalpy state, is sought by reshuffling the air parcels both horizontally and vertically. Here, more precisely, GCAPE is defined as APE considering only the vertical redistribution of air parcels in order to define a reference state.

5. GMS (gross moist stability): this concept originally introduced by Neelin and Held (1987) is a measure of moist convective instability based on a vertical integral of the moist static energy (cf. Sect. 4).

6. Boundary moist entropy: moist convection may be considered as a heat engine initiated by lifting of moist entropy in the boundary layer into free troposphere (cf. Paulus, 2011).

7. Free tropospheric temperature: this quantity becomes important in considering a particular type of CAPE closure based on parcel environment (cf. Sect. 5.4)

8. Water vapor: this is clearly an important variable because latent heating associated with condensation (and to lesser extent freezing) of water vapor leads to moist convective instability.

8a. Saturation fraction: the column-integrated water divided by that of the saturated column with the same temperature profile.

A focus may furthermore be placed to a particular vertical layer, leading to various more specific measures:

8b. Water-vapor mixing ratio in the PBL (planetary boundary layer): this is where the majority of water vapor is found in the atmosphere. Under a standard argument of the lifting-parcel theory, it is air lifted from this layer saturated and leading to condensation of water vapor originated from the PBL.

8c. Water-vapor deficit in lower troposphere: defined as a difference between the saturated specific humidity for the given observed (or modeled) temperature and the actual observed (or modeled) specific humidity (Redelsperger et al., 2002).

8d. Water vapor in the low-to-middle troposphere (LTMT): see discussions in Sect. 2.2.
9. Vertical wind shear: this controls the convective intensity by contributing to organization of convection (cf. Sect. 5.8).

Among all of these, CAPE and water vapor (moisture) are the two most commonly adopted variables for closures. However, potential importance of the other variables for closure can hardly be excluded a priori.

\subsection{Observational identification of convection- controlling variables}

We may argue that from an observational perspective, the closure problem reduces to that of identifying a nonlinear function of these control variables that define convective intensity. Clearly, a first step towards this goal is to identify the variables that control convective intensity observationally. Existing data analyses can be reviewed from this perspective.

From onset, however, we have to recognize a major difficulty in identifying "convection" from conventional measurements including satellite. Sherwood (1999) simply uses the satellite-measured infrared brightness temperature as a measure of convection. On the other hand, most of the other analyses discussed below use the precipitation as a measure of convection. Both the cloud height (as measured by the brightness temperature) and precipitation can be considered a good measure of convective activity over the tropics. However, a straight use of precipitation as a measure of convection in midlatitudes and higher latitudes becomes questionable because the precipitation is strongly controlled by the synoptic-scale processes. Zhang and Klein (2010) partially avoid this difficulty by limiting their analysis to the summertime of the Southern Great Plains, where the precipitation is known to be predominantly convective during this season.

Even over the tropics it is clear that either satellitemeasured infrared brightness temperature or precipitation rate is a very crude measure of convection. Both variables do not distinguish contributions from either convective core or anvils. All the following analyses do not distinguish whether convection is propagating or not.

Unfortunately, more direct measurements of, e.g., convective updrafts, are not possible with a conventional observational network. For this purpose, we need a special type of radar with a Doppler capacity, or probably better still, direct measurements of updrafts by flight penetrations into convection. Both measurements are rare. This is probably the most fundamental difficulty for identifying a closure formula from the observations. With those caveats in mind, we review the results from the existing data analyses here.

A "statistical" analysis by Sherwood (1999) would probably be the first example of such systematic analyses over the tropics. A multivariate analysis is performed on the sounding and the satellite data sets over the Tropical Western Pacific. His standard result is summarized in his Fig. 3. Low- to 
midtropospheric moisture is identified as the dominant factor regulating convection under this statistical analysis. No other variables, including CAPE, presents any significance.

A similar extensive statistical analysis is performed by Zhang and Klein (2010) for afternoon showers over the North American Southern Great Plains. A particularly interesting piece of information is found in their Fig. 9. This figure shows a statistical test of control parameters for triggering afternoon convective shower: longer bars have more statistical significance with positive and negative correlations to the left and the right. This analysis again shows that most of the above quantities do not show any significant role in defining a shower over a certain afternoon over the Southern Great Plains. A noticeable correlation is only found with the relative humidity both in the boundary layer and the lower free troposphere, a mid-level meridional wind, and surface temperature standard deviation. CAPE has no significant role, and the role of CIN is negligible. On the other hand, interestingly, a mean temperature gradient (cf. Sect. 3.1, 1) over 2$4 \mathrm{~km}$ represents a marginal significance. However, we should be cautious with the role of moisture in controlling convection because according to their Table 1 the lower-level relative humidity is not significantly correlated either with the total rain or maximum rain.

Barkidija and Fuchs (2013), based on measurements for 20 European stations for the period of 1972-2009 and the results of the Global Forecasting System (GFS) model, further shed light on this issue. They show that CAPE does not correlate with precipitation rate at any place on the globe, including the tropics and the middle latitudes as well as the higher latitudes. CIN shows a clear positive correlation, but the authors tend to suspect this is an artifact from the analysis (cf. Sect. 5.5). The saturation fraction (cf. Sect. 3.1, 8a) has a good correlation with precipitation rate, although in higher latitudes it does not represent a well-defined function as found in the tropics by Raymond et al. (2007: see their Fig. 3).

As the above relatively systematic studies show, the water vapor (or saturation fraction) is almost the only variable that shows a clear correlation with convection; notably, there are increases in lower-tropospheric water vapor that leads to increase in precipitation as shown by Raymond (1995); Brown and Zhang (1997); Sherwood (1999); Sherwood and Wahrlich (1999); Sobel et al. (2004); Mapes et al. (2006, 2009). Two theories are proposed by Raymond (2000) and Peters and Neelin (2006: see also Yano et al., 2012). This correlation should not necessarily be taken as a causality as it becomes clearer as we discuss further.

Observations in the tropics generally show that heavy rainfall is not correlated with CAPE in an obvious manner, but with decreased CAPE (Ramage, 1971; McBride and Frank, 1999, see especially their Fig. 1). Figure 8 of Xu and Randall (1998) also shows a similar point. Here, they take GCAPE rather than CAPE for this purpose: it shows that GCAPE is almost completely out of phase with convective precipitation.
Thus, (G)CAPE does not appear as a good measure of convective instability. A similar point is also made by Thompson et al. (1979); Wang and Randall (1994). We refer to Sects. 5.4 and 5.6 for a possible explanation for such CAPE behavior.

Overall, those studies may be criticized as being too crude to be useful for defining parameterization closure. However, it is important to recognize that even those simple analyses face difficulties in relating convection-controlling variables listed in Sect. 3.1 with an observational convection measure in any meaningful manner.

\section{Perspective from the tropical large-scale dynamics: inferences from linear stability analysis}

As the discussions of the last section shows, it is not easy to identify a nonlinear function of convection-controlling variables that defines convective intensity from observations. Thus, we now turn to a more theoretically based general approach.

As an example of such an alternative approach, in the present section we take a particular theoretical perspective for the tropical large-scale dynamics (cf. Yano and Bonazzola, 2009, as a review): tropical large-scale convective variability is controlled by linear instabilities arising from coupling between convection and large-scale dynamics. Kiladis et al. (2009) provide an observational review from this perspective (but see also Yano et al., 2009; Delayen and Yano, 2009 , for an alternative view). Under this framework, various closure hypotheses can be introduced, and the obtained instability characteristics of a theoretical system under a given closure can be examined. We expect that a consistency of these with observations provides a measure of physical relevance of the adopted closure.

We would like to expect that these theoretical analyses lead to more robust conclusions than the aforementioned observational studies. However, one has to inevitably choose a particular theoretical approach, especially for a cloud model, so a question of the generality of the results always remains.

Fuchs and Raymond (2002, 2005, 2007); Raymond and Fuchs (2007); Fuchs (2007); Fuchs et al. (2012) and others have performed extensive work on large-scale waves in the tropics (see also Raymond et al., 2010, as a review). As it turns out, from a point of view of coupling of the large-scale disturbances and convection in the tropics, CAPE closure is irrelevant. Especially, they found that a CAPE closure does not produce any interesting large-scale solutions (Fuchs and Raymond, 2002; Fuchs, 2007). On the other hand, they found that for convectively coupled Kelvin waves, convective inhibition (CIN) plays an important role (Raymond and Fuchs, 2007, 2009).

Here, as a major departure from more classical studies such as those based on wave CISK (conditional instability of the second kind: Hayashi, 1970, 1971; Lindzen, 1974, 
see also Sect. 5.1), moisture (or any equivalent variable) is explicitly considered as a prognostic variable in addition to standard variables for the dry primitive equation system. As a result, in addition to conventional equatorial-wave modes, another mode called "moisture mode" arises. The moisture mode is, as the name suggests, typically characterized by a dominance of the moisture field relative to the temperature field (Neelin and Yu, 1994; Sugiyama, 2009a,b; Fuchs et al., 2012).

The series of studies suggests that this moisture mode might be an underlying mechanism for many tropical disturbances, such as the Madden-Julian oscillations (MJO: Kiladis et al., 2005), easterly waves(Reed and Recker, 1971; Reed et al., 1977; Cho and Jenkins, 1987), and westerly wind bursts (Yano et al., 2004), when a moisture closure is considered. This moisture closure includes the dependence on gross moist stability (GMS); negative gross moist stability acts in a way that produces the instability in the moisture modes (Raymond et al., 2010; Raymond and Fuchs, 2007). If the models do not have the moisture closure, many disturbances in the tropics cannot be reproduced. These include the Kelvin waves, Rossby waves, inertio-gravity waves, moisture mode. The instability mechanism of those disturbances and the impact of different precipitation closures is examined. It is found that the introduction of CAPE into closure does not affect the overall structure of both linear dry and moist modes, but they are simply decayed by the CAPE closure (Fuchs and Raymond, 2002; Fuchs, 2007).

Here, GMS can be understood in terms of moist static energy as it was originally introduced by Neelin and Held (1987). Alternatively, it can also be defined in terms of moist entropy: a definition adopted here (Raymond et al., 2007, 2010). Arguably, GMS is an important part of moisture closure as a way of destabilization. The other possibility is to invoke radiative-convective instability (RCI: Fuchs and Raymond, 2002, 2005, 2007). In the latter case, a moisture closure can be considered without GMS. In that case the moisture modes are equivalent to the modes obtained by using the weak temperature gradient approximation (Sobel et al., 2001), i.e., assuming that the moisture perturbation is larger than the temperature perturbation. If there is no RCI or GMS, the moisture modes are stable. Another important ingredient is to take into account the two vertical modes in stability analysis (cf. Fuchs and Raymond, 2007).

A CAPE-based adjustment description only gives a damping mode, as emphasized by Emanuel et al. (1994) as moist convective damping. They further emphasize that an extra effect such as wind-induced surface heat exchange (WISHE: Yano and Emanuel, 1991) is required in order to induce a growing mode. However, in the present series of studies, no instability is found for realistic wavelengths even when WISHE is added. Though the result virtually contradicts an earlier study on WISHE instabilities assuming a single vertical mode (Emanuel, 1987; Neelin et al., 1987; Yano and Emanuel, 1991), the result is also consistent with Mapes
(2000) and Majda and Shefter (2001). Nevertheless, WISHE plays a role in providing a propagation mechanism to moisture mode (Fuchs and Raymond, 2002, 2005).

The linear stability analysis reviewed in this section tends to confirm the observational diagnosis reviewed in the last section: the moisture closure predicts instabilities consistent with observations, whereas the CAPE closure only leads to damping modes. The WISHE mechanism does not contribute to an instability either. An important role of CIN and GMS is suggested.

\section{Further theoretical considerations}

In this section, attempts are made to discuss pros and cons for both moisture and CAPE-based closures from more general perspectives. Issues with the high-resolution limit are discussed separately in Sect. 5.7.

\subsection{Moisture-based closure}

The moisture-based closure loosely assumes that a largescale supply of moisture is balanced by a consumption by convective processes. However, the definition of "large-scale supply" varies from scheme to scheme. The simplest choice is to consider only the large-scale convergence, but many schemes also include the surface flux effect. One may argue that moisture is central because deep convection is moist; moist convective instability is induced by bringing moist air to saturation. Deep convection is part of the water cycle.

The moisture-based closure has been a popular approach since its original proposal by Kuo (1974). This idea is intimately related in people's mind with the notion of largescale uplifting or lower-level convergence leading to moist deep convection. Such a process leads to water condensation. The latter, in turn, leads to convective instability. For this reason, the moisture-based closure may even be conceptually replaced by an assumption of convection proportional to the low-level large-scale convergence. The latter is a popular idea originated from CISK (conditional instability of the second kind: Charney and Eliassen, 1964), which is then generalized into wave CISK (Hayashi, 1970, 1971; Lindzen, 1974).

However, it is rather within a narrow context of tropical deep convection that low-level large-scale convergence is invoked as a closure condition. A trivial example for demonstrating the irrelevance of low-level large-scale convergence for convection is shallow convection (e.g., stratocumulustopped boundary-layer convection: Lilly, 1968; Schubert et al., 1979). Those non-precipitating convective clouds are typically maintained under large-scale descent. In the literature, as far as the authors are aware, large-scale uplifting is never mentioned as a mechanism for transformation of stratocumulus-topped boundary-layer convection into trade cumuli, for example. 
It is true that non-precipitating convective clouds are also maintained by moisture supplied from the surface. However, the moisture transport is almost exclusively taken care of by eddy vertical transport, an aspect that is totally neglected in standard moisture closures. In this respect, a picture of convection driven by large-scale convergence only has a limited applicability, and it may not always be true even in deepconvection contexts.

As discussed in Sect. 3.2, the availability of water vapor in a given atmospheric column is a good indicator of convective precipitation over the tropics. Theoretical studies on tropical convectively coupled linear waves in Sect. 4 also favor the moisture-based closure. On the other hand, as emphasized by Emanuel et al. (1994), at a very philosophical level, this closure has a causality problem by assuming convection is driven by moisture rather than by buoyancy, as already emphasized in Sect. 2. As a result, convection is made to depend on something that is the result of convection.

\subsection{CAPE}

To repeat the point, convection is ultimately driven by buoyancy. By taking a vertical integral of buoyancy, arguably, CAPE is a physically more relevant measure of convective instability, compared to the moisture. Fundamental importance of CAPE in the energy cycle of convection is hardly overemphasized. However, various limitations of the CAPE concept must also be recognized.

First of all, CAPE is based on a Lagrangian trajectory analysis of air motions. Recall that a work, $\mathrm{d} W$, performed on a unit mass of air by bouyancy, $b$, by lifting over a distance, $\mathrm{d} z$, is given by

$\mathrm{d} W=b \mathrm{~d} z$.

The vertical integral of the above leads to CAPE. However, we should keep in mind that this integral is useful only when we strictly follow a Lagrangian framework moving along an individual air parcel. Standard dynamical formulations rather follow an Eulerian description.

As well demonstrated by Rennó and Ingersoll (1996), the role of CAPE is best established in the convective energy cycle when a closed circulation is assumed. In the original paper on CAPE (Moncrieff and Miller, 1976), it is introduced as a part of Bernoulli integral (see e.g., their Eq. 8). Thus, the role of the counter-acting dynamic pressure, $\Delta p$, must be properly taken into account when the circulation is not closed.

\subsection{Moisture vs. CAPE closures}

The moisture-based closures may be criticized on a basis of causality. This may not be a real issue because the closure treats the large-scale average conditions for deep convection, dominated by availability of moisture (but not CAPE as observations show, cf. Sect. 3.2). We should also keep in mind that the parameterization does not attempt to resolve the individual buoyancy-driven motions. This last point may be understood by taking, as an example, a prediction of the motions and patterns of sand dunes driven by the wind without predicting the motion of each grain of sand.

Our operational experiences (P. Bechtold, personal communication, 2012) tell that moisture-based closure works less well than the CAPE-based closure. A well-known problem with the moisture-based closure is its tendency for gridpoint storms associated with a spurious increase of CAPE, as demonstrated by an idealized analysis (Yano et al., 1998, see their Figs. 2 and 5). Also, a moisture convergence closure can cause an artificial CISK (cf. Ooyama, 1982). Thus, observationally identified correlation does not necessarily lead to a useful closure.

Drawbacks of the moisture closure should not be overemphasized either. Both moisture and thermal structure of the atmosphere (e.g., CAPE) are altered by convection. Ultimately, the real problem with the two closures may be that the subgrid-scale variability of humidity, forced ascent, and environmental temperature are not statistically parameterized properly, so that the true dependency on local CAPE and on the degree of forced lifting up to the moisture-dependent LFC (level of free convection) are not included in them.

CAPE is no doubt a very appealing quantity for measuring a degree of moist-convective instability of a system based on a notion of a conditional instability induced under a parcellifting process. However, CAPE does not provide a degree of convective intensity (e.g., tropical precipitation) by observational diagnosis, as already discussed in Sect. 3.2. Still, CAPE closure works the best among the available options in our operational experiences (P. Bechtold, personal communication, 2012). In the following three subsections, we consider variants of the CAPE closure with a hope of filling a gap of the two opposite perspectives: observational and operational.

\subsection{Parcel-environment CAPE closure}

A major shortcoming of taking "total" CAPE as a measure of convection comes from the fact that it varies almost simultaneously with convection, so observations of correlation between CAPE and rainfall do not tell us much about causality, as already discussed in Sect. 3.2. Zhang (2002) proposes an alternative formulation called parcel-environment CAPE closure. Note that, in fact, the original demonstration of Arakawa and Schubert (1974) for quasi-equilibrium (their Fig. 13) is also based on this formulation. Zhang (2002) notes that the change in CAPE is due to two components: those coming from the free tropospheric environment and those from the boundary layer. He suggests that the former is related to the convection, but not a part coming from the latter, leading to a concept of parcel-environment CAPE closure ${ }^{5}$. Under the same spirit, Donner and Phillips (2003) examine

\footnotetext{
${ }^{5}$ The suggestion from Raymond and Herman (2011) about rapid equilibration of the environment's CAPE due to latent heat release
} 
CAPE closures by analysing observations from Oklahoma and the tropical Pacific and tropical Atlantic. They observe that the parcel-environment closure is closest to the observations, and that the relaxed and strict quasi-equilibrium closures involving total CAPE are generally not satisfied, especially over land. Therefore, the paradox or challenge for us is to explain why the parcel-environment closure is observed to be well satisfied and why total-CAPE closures are observationally less satisfied.

Donner and Phillips (2003) find that the large-scale average of total CAPE is irrelevant for deep convection over a mesoscale area. The total CAPE varies very rapidly in a noisy manner because it is controlled by fast-varying boundary layer processes. Whenever convection happens, for example, it is disturbed by cold pools from downdraft air into the boundary layer. As a result, CAPE on the convective scale has much spatial variability.

There are two possibilities for explaining the observed validity of parcel-environment closure: first, mesoscale systems of deep convection evolve more slowly with time scales of half a day or so for them to respond to the fast-varying total CAPE. Instead, they can only respond to the similarly slow variation of the environmental free-troposphere's thermodynamic structure. Second, only the amplitude of "subgridscale" variability of total CAPE on the convective scale may be relevant for the buoyancy of updraft parcels.

from precipitation, as discussed in Sect. 2.2, may give further insight about why the strict convective quasi-equilibrium closure is invalid for deep convection. As the convection is deep, it extends above the region of precipitation production. A new version of quasi-equilibrium could be restricted to convection in the lower troposphere and buoyancy integrated only over the lower troposphere, but this would need to be verified by field observations of cases such as GATE, TOGA, ARM, and KWAJEX. Donner and Phillips used field observations to show that total CAPE fluctuates greatly due to the boundary layer's noisy control of it so that deep convection's consumption cannot keep up with it and there is no strict quasi-equilibrium of CAPE. The component of the total CAPE in the lower troposphere would be expected to be similarly noisy, and similarly unequilibrated by convective consumption. So, it does not seem that an adjusted state applied only to the lower troposphere would be better than parcel-environment closure.

A main problem with the parcel-environment closure is that it fails certain thought experiments of extreme situations. Though empirically well supported, it rather lacks in robust physical basis. From a point of view of the parcel dynamics, a convective parcel is essentially driven by buoyancy, whereas buoyancy depends on both the parcel properties and environmental profile. Yet the parcelenvironment closure neglects the component of buoyancy due to parcel properties, by balancing only that due to the parcel's environment against the convective intensity. For example, if there were extreme surface heating, as there is over land in summertime in midor low latitudes in the afternoon, and if there is no tendency of CAPE due to the parcel's environment, then convection may still occur in reality. But that convection would be disallowed by the parcel-environment closure, unrealistically.
An important role of "subgrid-scale" variability of CAPE may furthermore be considered in the following manner. Let us consider how forced vertical lifting of parcels to their level of free convection influences the closure problem. The intensity of individual convective elements over a mesoscale grid box is presumably determined by local conditions. Each and every convective element can be maintained only when thermals in the boundary layer rise to their level of saturation. So, the depth of the boundary layer and the amplitude of variability of humidity and temperature inside it, which determine how often parcels are lifted by chance beyond saturation so as to form a convective cloud, may be considered a part of the closure problem determining the overall large-scale convective mass flux. Thus, an approach for probability distribution of convective-scale variability of total CAPE inside each global model's grid box would ultimately be required in order to make a closure formulation more complete.

\subsection{PBL-based closure}

A counterpart approach against the parcel-environment closure discussed in the last subsection (Sect. 5.4) is to try to close a convection parameterization based on a PBL (planetary boundary layer) process. Here, CIN plays a key role.

It is a commonly accepted view (to which we disagree) that a convection parameterization requires a trigger, and CIN is a typically adopted quantity for a trigger. Intuitively, a trigger is required based on the fact that convection rarely happens in spite of the fact that a finite value of CAPE always exits. It is normally interpreted that convection is triggered in order to initiate its life cycle, then it is terminated when its life cycle is over. Thus, in any convection parameterization, both triggering and termination conditions are required (a notion that we disagree with. See Sect. 5.6, Yano and Plant, 2012b).

Mapes (1997: especially see his Fig. 4, also Sect. 6.4 of Stensrud, 2007) emphasizes that a relative importance of trigger depends on the scale of convective systems. In order to elaborate this point, he proposes two major convective regimes depending on whether the convection activity is controlled by the increase of instability (equilibrium control), or by the processes overriding or suppressing CIN (activation control). When convective activity is on a large scale (e.g., the whole tropical band), convection responds to radiative destabilization quite continuously, maintaining a state of near radiative-convective equilibrium, without any apparent role for CIN. On the other hand, when convective activity is on the mesocale, the spatial organization of convection is to be found into arcs, or lines, related to the existence of various PBL processes overriding the CIN, such as gust fronts, sea and land breezes, dryline convergence, etc.

Mapes (2000) in turn applies the concept of activationcontrol principle in order to define the convective intensity. His main proposal is to set the convective intensity proportional to $\exp (-\mathrm{CIN} / \mathrm{TKE})$, with TKE the turbulence kinetic 
energy of PBL. More precisely, Mapes (2000) adds a prefactor proportional to $\mathrm{CAPE}^{1 / 2}$ to this closure, but this detail is not followed by subsequent works. A closed expression for TKE must also be supplied, but none of the work following Mapes (2000) invokes CAPE for this purpose either. As a result, essentially, we arrive at a closure based on CIN instead of CAPE. Though the idea of Mapes (2000) is also followed by Bretherton et al. (2004) and Hohenegger and Bretherton (2011) for shallow-convection parameterizations, from operational point of view (P. Bechtold, personal communication, 2012) the CIN closure is not reliable, being too sensitive to details of the boundary layer. It also does not respond to destabilization in free atmosphere induced by mid-level large-scale forcing (cf. Sect. 5.4).

More importantly, we should note an inconsistency of the logic here: the original activation-control principle (Mapes, 1997) simply says triggering under low CIN is important, but it says nothing about a closure, whereas Mapes (2000) reinterprets this principle for defining a closure. We should clearly distinguish between the use of CIN as a trigger, e.g., with a CAPE closure, and as a closure condition by itself. Here, the issues between trigger and closure are mixed up.

It may be argued that CIN is overabused in the convection community. Extensive discussions from perspectives against use of CIN as a closure and a triggering formulation, as well as a very concept, are given in Yano (2011). We summarize below the main points succinctly with some supplementary remarks. Readers are strongly encouraged to refer to the original comment (Yano, 2011) for the full discussions.

- Inconsistency between Mapes (1997) and Mapes (2000) may stem from the fact that the activation control principle of Mapes (1997) is fundamentally inconsistent with the basic premises of mass-flux parameterizations based on steady-plume hypothesis. Under this formulation, an ensemble of convective plumes is assumed always in equilibrium with the large-scale environment. Transient behavior of individual plumes, especially their individual triggering process, which may well be conceptually considered by a parcel-lifting process associated with a presence of CIN, is not at all in concern. As a result, the issue of "triggering" is, from this strict point of view, beyond the scope of the given parameterization formulation. ${ }^{6}$

\footnotetext{
${ }^{6}$ If the argument so far is not convincing for a reader, one has to further consider in the following manner: here one clearly needs to recognize that an "ensemble" of plumes as a whole retains a steady state under the steady-plume hypothesis. Under this framework, evolution of individual convective plumes in convective time scale (including their trigger) does not play any role in the formulation. By strictly focusing on the behavior of the plumes as whole as an ensemble under a balance with a slowly varying large-scale state, what happens with an individual plume and how a given plume influences all the others are not included in the given formulation. It may well be possible that a trigger of a single plume lead to growth
}

We need a radical modification of mass-flux parameterization in order to introduce the activation control principle of Mapes (1997). Under this radical modification, evolution of individual convective plumes must be treated in fully prognostic manner, instead of treating them as an ensemble as a whole. Such a prognostic formulation for convective plumes under mass-flux formulation is already outlined by Yano et al. (2005a) and Yano (2012b) and is called NAM-SCA. Test of its performance under a single dry plume configuration is reported by Yano and Baizig $(2012)^{7}$. Although we may well need a condition to turn on a conventional convection parameterization for practical purposes, this issue must be carefully distinguished from that of the triggering of individual convective plumes ${ }^{8}$.

- A steady plume, which the standard mass-flux parameterization is based on, is by definition driven by buoyancy (or more precisely, vertical buoyancy flux, cf. Sect. 5.6) integrated vertically from the bottom to the top of the given plume. Hence, only the total CAPE defined as a sum of both positive and negative contributions matters for its evolution ${ }^{9}$. CIN may become an issue only when a transient initial phase of a single plume is considered. For a steady plume, there is no reason to single out a role of CIN away from the other part of CAPE. As discussed in Sect. 5.6, the convective energy cycle is better defined in terms of the cloud work function or PEC (cf. Sect. 3.1, 3, 3a), in which a contribution of negative buoyancy is in no place considered "separately" under a standard mass-flux formulation.

- More physically speaking, $\mathrm{CIN}$ is a misleading quantity arising from an artificial use of a lifting parcel. In wellmixed boundary layers both over tropics and midlatitudes, physically such a barrier should not exist because

of an ensemble plume as a whole. However, Mapes' activationcontrol principle does not discuss this at all. Such a theory is yet to be presented and fully formulated.

${ }^{7}$ In order to move to such a fully prognostic formulation, and to consider trigger of plumes explicitly, first of all the separation of the variables (Eq. 1) traditionally assumed must be abandoned.

${ }^{8}$ The issue of the former is how an ensemble of convective plumes starts as a whole. Mapes' activation-control mechanism only refers to triggering of individual convective plumes, and not at all to an ensemble of convective plumes as a whole. The given mechanism does not even say anything about the behavior of an ensemble convective plume. These two completely different issues, behavior of individual plumes and of an ensemble as a whole, must carefully be distinguished. If evolution of ensemble convective plumes is properly described, trigger may never become an issue as suggested by Yano and Plant (2012b), in principle.

${ }^{9}$ Here, recall that buoyancy is defined in terms of a difference of the virtual temperature between convection and the environment in evaluating CAPE. Note that the scale for the environment is not specified in this argument. 
the motions of parcels in a layer are buoyancy-driven by nature. Actual individual parcels typically feel buoyancies positively correlated with the vertical velocity, unlike an artificially defined lifting parcel. If CIN is redefined, more energetically consistently, as a negative contribution of the buoyancy flux (cf. Eq. (2) in Sect. 5.6 below), we do not see such a negative buoyancy barrier as shown in Fig. 2 of Yano (2003) and Fig. 1 of Yano (2011). As will be explicitly derived in Sect. 5.6, it is the vertical buoyancy flux, rather than buoyancy itself, that defines the generation rate of convective kinetic energy. A normalized vertical integral of the buoyancy flux leads to PEC and the cloud work function.

- The role of CIN in convective dynamics is often interpreted in a rather arbitrary manner. For example, Chaboureau et al. (2004) argue that convection is triggered under a diurnal cycle when CIN becomes sufficiently small (their Fig. 3b). However, they do not explain why convection is maintained afterwards in spite of the fact that CIN increases again. It is well possible that continuity of convection is due to a compensation effect by, for example, a presence of more turbulent kinetic energy in the boundary layer. However, the reference in concern does not verify this point ${ }^{10}$.

- Not all the existing theories agree upon the point that CIN inhibits deeper convection, especially when it is more properly reinterpreted as a vertically integrated normalized buoyancy flux (cf. Sect. 5.6). An example is the "decoupling" theory proposed by Bretherton and Wyant (1997) for explaining the transition of the cloudtopped boundary layer into deeper convection (trade cumuli). Here, the decoupling is realized as a development of negative buoyancy flux at the top of the subcloud layer as the sea surface temperature increases. Thus, under this theory, CIN (i.e., negative buoyancy flux) positively contributes to triggering deeper convection rather than suppressing it. In other words, large CIN triggers convection (trade cumuli) according to Bretherton and Wyant, whereas small CIN triggers convection according to Mapes' activation control. These two theories clearly contradict each other.

The notion of triggering under lower CIN is more recently further elaborated by introducing the concept of ALE (available lifting energy) as a counterpart for defining the activation threshold for CIN (Rio et al., 2009, 2012; Grandpeix and Lafore, 2010). Furthermore, a measure of kinetic energy generation rate is introduced as ALP (available lifting potential). The formulation assumes that deep convection is controlled

\footnotetext{
${ }^{10}$ Here, we do not argue any place that CIN plays no role in convective dynamics. We merely argue that many studies are performed in so much arbitrary manner that it is hard to derive any definite conclusion on this question.
}

by subcloud processes providing energy and power to lift and sustain convection. Boundary-layer thermals and cold pools provide ALP, which is used to compute the cloud-base massflux. In addition, the introduction of the cold pool parameterization allows the introduction of a subgrid variability of CAPE and CIN within a model grid box as convection does not see mean grid-box environment but only part outside cold pools (cf. Sect. 5.4). The formulation has already been implemented into a global climate model (Hourdin et al., 2012; Rio et al., 2012). However, exactly the same criticism as Mapes' activation control by CIN applies here ${ }^{11}$ (see also Yano, 2012a). Note that ALP is not listed in Sect. 3.1 because its definition depends on a boundary-layer scheme adopted in a model.

\subsection{Cloud work function and energy cycle of convective system}

How important it may be in convective processes, CAPE is ultimately only a cheap substitute for a true energy conversion process. CAPE, being based on a simple lifting-parcel theory, has the two major limitations: (i) use of an undiluted parcel buoyancy, (ii) absence of a vertical momentum factor.

The first point appears to be widely appreciated: CAPE is calculated by assuming a lifting parcel without any mixing with the environment. In a more realistic situation, a rising air parcel is more likely to experience substantial mixing with the environment. As a result, buoyancy is "diluted" compared to the standard lifting-parcel value. This effect becomes critical, especially when the lower free troposphere is extremely dry as aftermath of a dry intrusion from midlatitudes in the Tropical Western Pacific (cf. Redelsperger et al., 2002). Under this situation, a conventional CAPE suggests huge convective instability, while deep convection is completely suppressed observationally. However, Donner and Phillips (2003) find that the diluted CAPE (cf. Sect. 3.1, $2 b$ ) is still often not a good indicator of convection.

The second point may appear less obvious, but it is simply understood by noting that CAPE is only an approximate substitute for a true energy conversion process, unless we take a Lagrangian description of the motions (cf. Sect. 5.2) as adopted by Moncrieff and Miller (1976) and Rennó and Ingersoll (1996): CAPE provides a work performed on a particular air parcel when an integral is performed along the parcel trajectory (cf. Eq. 1).

Now, we are usually interested in a generation rate of the kinetic energy at a fixed spatial point. For this purpose, we rewrite Eq. (1) by noting that the Lagrangian parcel lifting, $\mathrm{d} z$, is related to the vertical velocity, $w$ by

$\mathrm{d} z=w \mathrm{~d} t$

\footnotetext{
${ }^{11}$ Their formulation also still remains under a framework of the steady-plume hypothesis without any explicit consideration of evolution of individual plumes.
} 
where $t$ is the time. By substituting the above into Eq. (1), a local generation rate of kinetic energy is given by

$$
\frac{\mathrm{d} W}{\mathrm{~d} t}=b w .
$$

Clearly the right hand side is the vertical buoyancy flux. Thus, from an Eulerian point of view, it is the vertical buoyancy flux that controls the generation rate of kinetic energy, rather than the buoyancy itself (cf. Yano et al., 2005b).

A more formal consideration of the convective energy cycle along this line leads to the notion of cloud work function as originally introduced by Arakawa and Schubert (1974). It provides a more consistent measure for the convectivekinetic energy generation efficiency. The cloud work function can be estimated as PEC (potential energy convertibility, cf. Sect. 3.1, 3a) from cloud-resolving modeling as discussed by Yano (2003), and Yano et al. (2005b). Both works show from CRM experiments that PEC is indeed much better correlated with convective precipitation than CAPE (see Fig. 1 of Yano, 2003, Figs. 1d, 3-5c of Yano et al., 2005).

As shown in Arakawa and Schubert (1974), the generation rate of kinetic energy, $K_{\lambda}$, for a given convection type, $\lambda$, is given by $A_{\lambda} M_{\lambda, \mathrm{B}}$, where $A_{\lambda}$ and $M_{\lambda, \mathrm{B}}$ are the cloud work function and the cloud-base mass flux for the given convective type designated by $\lambda$, respectively. Note that $A_{\lambda} M_{\lambda, \mathrm{B}}$ is essentially a vertical integral of the right-hand side of Eq. (2), being consistent with the argument so far.

In turn, the cloud work function, $A_{\lambda}$, is modified by a rate

$\sum_{\lambda^{\prime}} \gamma_{\lambda, \lambda^{\prime}} M_{\lambda^{\prime}}$

defined in terms of a matrix $\gamma_{\lambda, \lambda^{\prime}}$ that characterizes the efficiency of a particular convection type, $\lambda^{\prime}$, in modifying the other convection type, $\lambda$, given a specific cloud-base mass flux, $M_{\lambda^{\prime}}$.

Note that this energy-cycle system (as more precisely given by Eqs. (132) and (142) in Arakawa and Schubert, 1974), consisting of three variables, $K_{\lambda}, A_{\lambda}$, and $M_{\lambda}$, for each convective type, is closed once a certain relationship is established between two of the above variables. It is most logical to link $K_{\lambda}$ to $M_{\lambda}$, and we may in general set

$$
K_{\lambda} \propto M_{\lambda}^{p}
$$

with an unspecified exponent $p$. Randall and Pan (1993), and Pan and Randall (1998) close the above system by assuming $p=2$, and propose to use this prognostic formulation in place of conventional closure for running the convection parameterization of Arakawa and Schubert (1974).

Yano and Plant (2012b) rather suggest $p=1$ is a more consistent choice based on statistical behavior of idealized cloud-resolving simulations (Emanuel and Bister, 1996; Shutts and Gray, 1999; Parodi and Emanuel, 2009). One of the beauties of this alternative choice is that as a result, the system spontaneously represents a life cycle of convective systems consisting of discharge and recharge under constant external forcing due to its nonlinearity, as shown in Yano and Plant (2012b). For example, this model provides a very simple explanation for delay of convective initiation under a diurnal cycle against solar forcing. Most importantly, a life cycle of convective ensemble is described here without trigger and suppression conditions (cf. 2nd paragraph, Sect. 5.5).

However, unfortunately, Randall and Pan (1993) and Pan and Randall (1998) do not consider a full implementation of the above prognostic formulation, but only consider the diagonal terms in the matrix, $\gamma_{\lambda, \lambda}$. This restriction physically means that the individual convection types, labeled by $\lambda$, evolve by themselves without interacting with the other convective types. This is the major restriction of their implementation.

These off-diagonal terms with $\gamma_{\lambda, \lambda^{\prime}}\left(\lambda \neq \lambda^{\prime}\right)$ represent interactions between different convection types in the convective energy cycle. Interactions between different convection types are expected to be important in many problems. For example, the transformation of shallow convection into deep convection can easily be described under the interactions between shallow and deep convection (Yano and Plant, 2012c).

It is important to realize that the convective energy cycle, outlined here by invoking Eq. (2), can be derived under a formal procedure of the energy integral of an ensemble system of convective plumes (cf. Yano and Plant, 2012b). Equations (132) and (142) in Arakawa and Schubert (1974), obtained in this manner, thus provide a robust basis for closing a convection parameterization. Recall that Arakawa and Schubert's convective quasi-equilibrium closure is defined as a steady condition for their Eq. (142). Being based on a formal procedure, it also provides a solid basis for analyzing various convective-resolved simulations as well as interactions between convection and large-scale dynamics, in an alternative manner than discussed in Sect. 4.

\subsection{High-resolution limit ${ }^{12}$}

One of the issues to be taken into account in defining the closure assumption is a possibility that a dominant physical process defining the convective intensity may change with the scale, and henceforth also with the model resolution (cf. Bister, 1998). Here, it may be argued that as moving to higher resolutions, convective drafts must be more explicitly computed by model dynamics.

Though some exploratory studies have been performed for high-resolution limit (Gerard and Geleyn, 2005; Gerard, 2007; Kuell , 2007; Gerard et al., 2009), no study

\footnotetext{
${ }^{12}$ The present subsection more precisely asks the following question: what should we do with a given high resolution? This is an operationally oriented question, because a resolution is usually fixed (for a substantial period until the model is upgraded), and we are struggling with the improvements of the forecasts. For this reason, we do not explicitly consider the resolution dependence, although it is clearly a valid question and worthwhile to address.
} 
systematically focused on the closure issue has been yet reported. The present subsection presents theoretical reflections on this issue with some preliminary results supporting our arguments.

The behavior of the subgrid-scale parameterization of a model is related to a numerical algorithm adopted. Its behavior can substantially differ from what is expected if the averaging area is gradually narrowed from a simple statistical diagnosis. For instance, at a higher resolution, the model vertical profiles in cloudy regions are likely to become closer to moist adiabat, so that the buoyancy of a lifted parcel tends to decrease with increasing resolutions. The vertical velocity, $w_{\mathrm{c}}$, in subgrid-scale updrafts, is estimated from a given gridbox state, based on either a diagnostic or prognostic equation using a buoyancy in most of convection parameterizations. As moving towards high resolutions, the convective vertical velocity, $w_{\mathrm{c}}^{\prime}$, as defined as a deviation from a grid-box average, would tend to zero.

From a purely statistical point of view with a fixed largescale environment, the convective vertical velocity is defined by an ensemble average; thus, as the model resolution becomes higher, this ensemble size reduces, leading to a more stochastic behavior. Such a stochasticity leads to a greater chance of seeing a higher convective vertical velocity as the model resolution increases - virtually contradicting the conclusion just stated in the last paragraph. Note that such a purely statistical reasoning is misleading because the "environment" itself is highly inhomogeneous in high-resolution limit. A similar statistical behavior holds for the convective fraction $\sigma$ : at high resolution we are likely to observe larger convective fractions than at coarse resolution.

Concerning the closure we may expect the following situations:

- The above-mentioned reduction of buoyancy makes CAPE almost vanish within convective drafts. This argument could help the CAPE-based closures to guarantee an extinction (suppression) of convection in subgridscale schemes at high resolution properly without producing a perpetual grid-point storm. However, if the CAPE closure is used to determine the convective fraction, a vanishing convective fraction is produced at high-resolution limit in a counter-intuitive manner. Here, one of the difficulties behind is in properly defining an "environment" defining CAPE, which may be found beyond a grid box in the high-resolution limit. Furthermore, distributions of CAPE in the convective scale may somehow be taken into account in the closure, as already suggested in Sect. 5.4.

- As moving to high resolutions, the moisture convergence does not always reach a maximum as a parameterized convection follows its life cycle. Instead, at the heart of a half-resolved convective updraft, an increasing moisture convergence may be induced associated with an increasing updraft velocity. For this rea-
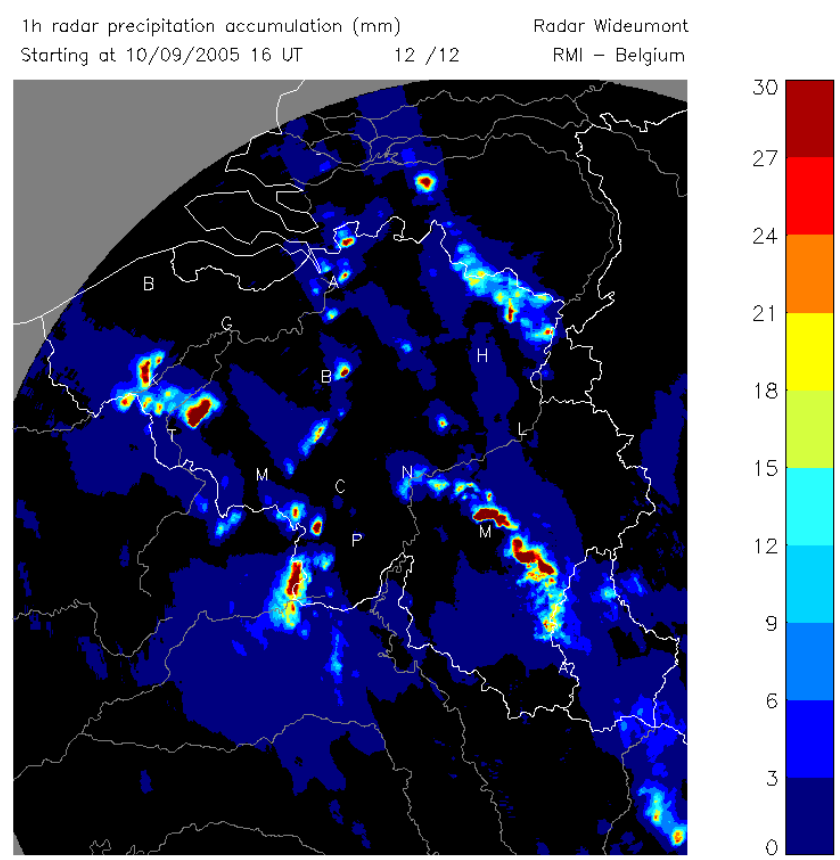

Fig. 1. $1 \mathrm{~h}$ accumulated precipitation - thunderstorm of 10 September 2005, Wideumont Radar, RMIB

son, the schemes based on a moisture-based closure are likely to experience difficulties in producing an extinction of the parameterized part of a convective event at high resolutions.

To illustrate some differences between CAPE and moisture convergence closures, we present a few preliminary results obtained with the Alaro model with a new prognostic deep-convection scheme, based on a perturbation approach. The model details are referred to in Gerard et al. (2009). The scheme includes a triggering similar to the Kain-Fritsch scheme (Kain, 2004): an entraining lifting air parcel is raised to its LCL (lifting condensation level), where it receives a buoyancy kick. The kick, conditioned by a threshold of the resolved vertical velocity, $\bar{w}_{\mathrm{LCL}}$, at LCL, allows the parcel to pass its LFC. Note that this is only a particular choice for trigger, and sensitivities of the model on trigger must also still be investigated in the same manner as for the closure. The moisture closure is as presented in Gerard et al. (2009) (cf. especially their Eq. 6). The CAPE closure includes a contribution of the downdraft on the boundary layer, and a unsaturated downdraft scheme (based on Betts and Silva Dias, 1979) is also included in the model.

By considering a case with very narrow thunderstorm systems in the observation (Fig. 1), we expect that the precipitation at $4 \mathrm{~km}$ resolution should be less than the extremes on the radar image. For this reason, we show the model-predicted precipitation (Fig. 2) in the same color code but with the half of the scales to the observed precipitation. The moisture convergence closure $(\mathrm{MC})$ yields more intense precipitation than 
$\mathrm{t} 4 \mathrm{~Pb} / \mathrm{:mean}=1.2, \max =39$

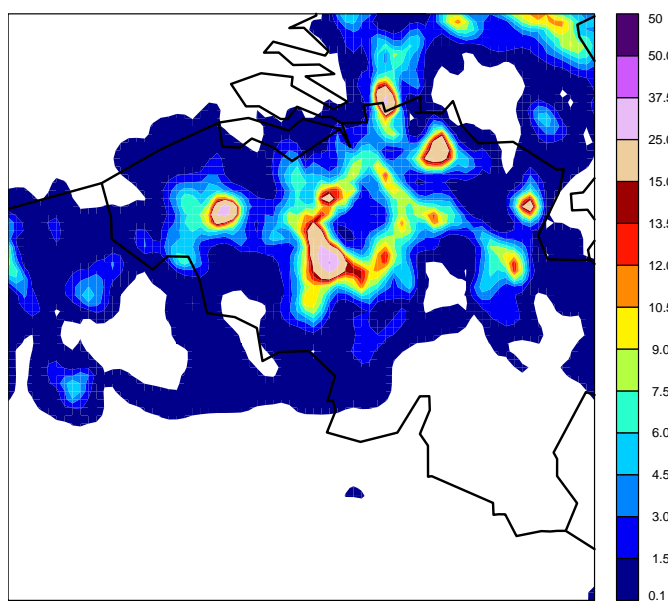

$\mathrm{t} 4 \mathrm{Pc} / \mathrm{:}$ mean $=0.6, \max =32$

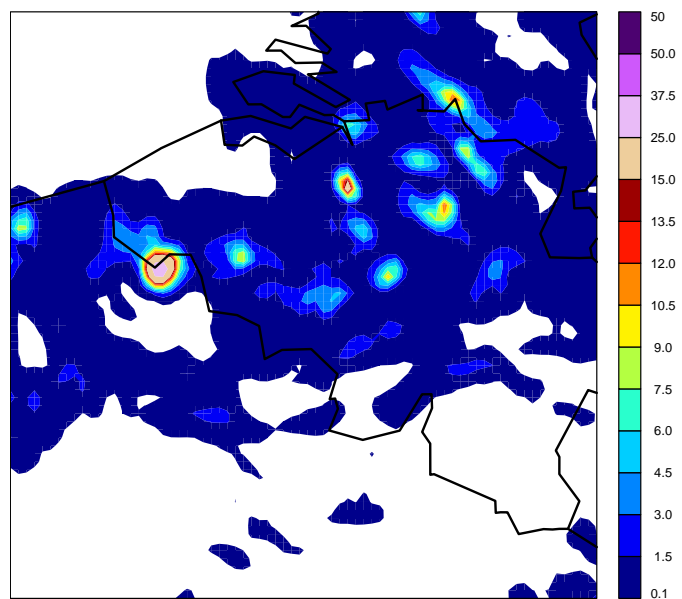

Fig. 2. Preliminary results of new prognostic convection scheme in Alaro model, $4 \mathrm{~km}$ resolution run on a limited area, with 41 vertical levels. Left: moisture convergence closure, right: CAPE closure. $1 \mathrm{~h}$ accumulated precipitation $(\mathrm{mm})$, precipitation scale is shown by a half scale of the radar image.

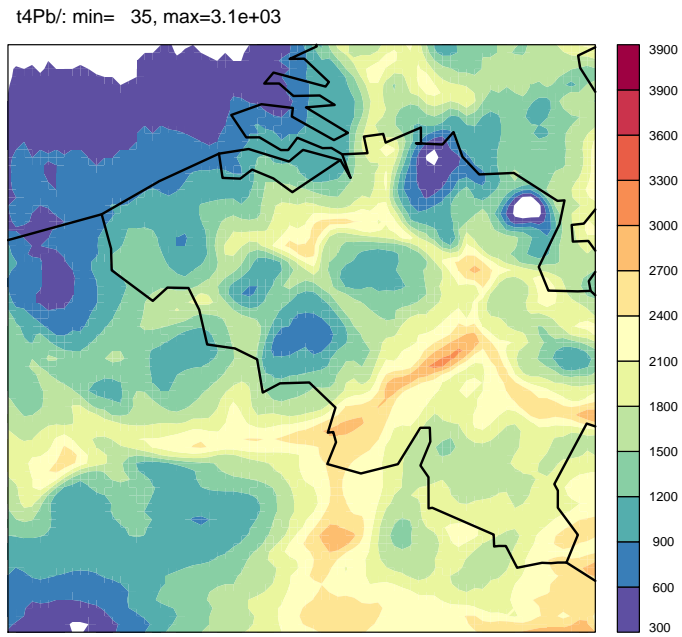

Fig. 3. The same as Fig. 2, but for a horizontal distribution of CAPE.

CAPE closure (CC). The MC precipitation field appears to be shifted to the northeast with respect to the radar image. In Fig. 3, the CAPE appears lower at places where the convective scheme is active. In the upper-right corner, $\mathrm{MC}$ gives precipitation that was not observed and reduces the CAPE, while CC allows the CAPE to sustain. In Fig. 4 we observe that MC yields more intense low-level moisture convergence, associated with precipitation. With CC, moisture convergence is well correlated with precipitation areas, though a substantial difference in structure is still noticed. The preliminary results presented here appear to support the notion of positive feedback of moisture convergence by writing a condition on an effect. It can furthermore lead to an erroneous evolution of the forecast model.

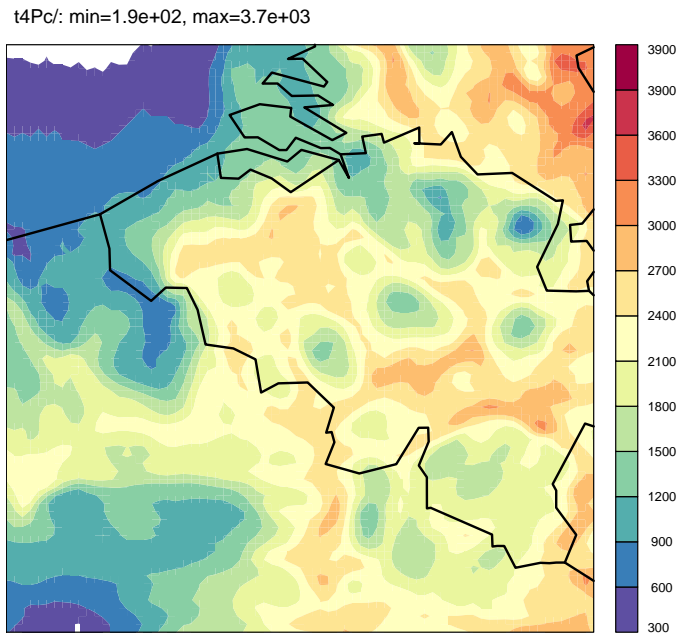

\subsection{Wind shear}

In closing our theoretical reflections on the closure problem, we consider the role of convective organization. We take the vertical wind shear as a specific example that, through its organization tendency for convection, contributes in defining the convective intensity.

It is observationally well known that the vertical wind shear tends to organize convection and to increase its longevity (cf. Klemp, 1987), and this tendency can also be demonstrated by numerical modeling (e.g., Weisman and Klemp, 1982). Various theories have been developed (e.g., Moncrieff and Green, 1972; Thorpe et al., 1982; Rotunno et al., 1988). The first two works link the wind shear with 

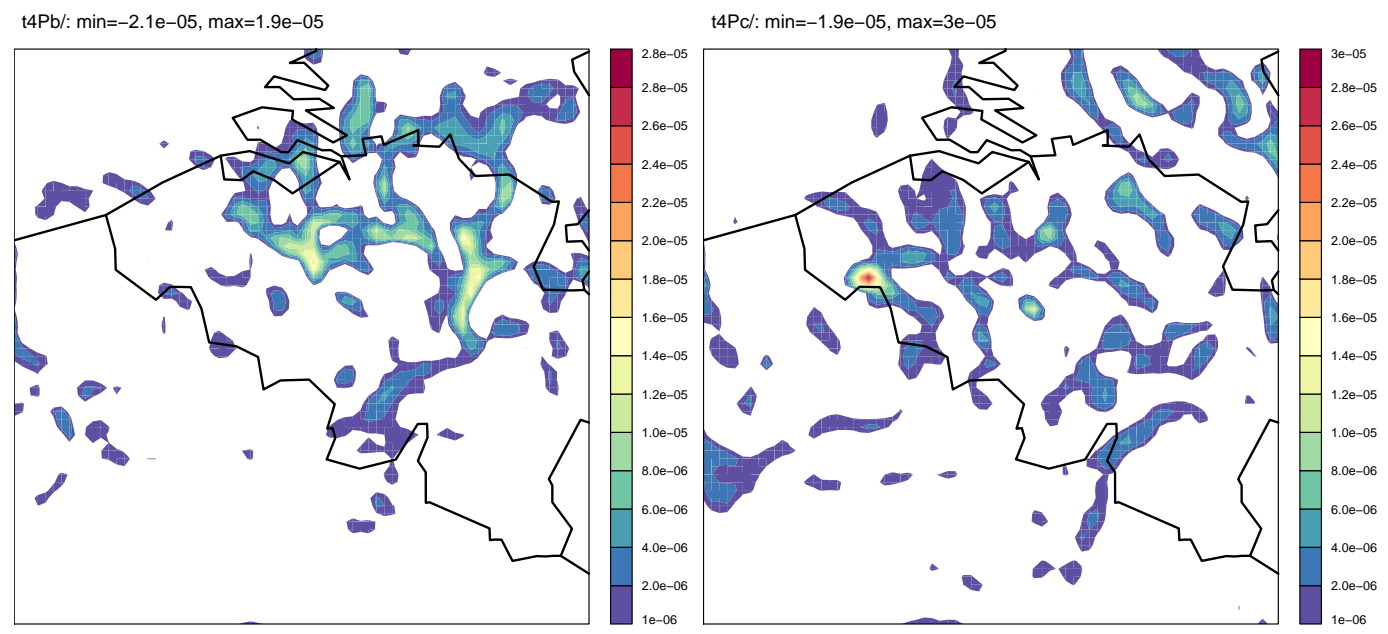

Fig. 4. The same as Fig. 2, positive low-level moisture convergence field.

the energy cycle of convection described by CAPE (cf. Sect. 5.6).

More specifically, the convective mass flux must depend on the longevity of individual cells of convection. This longevity determines the dehumidification of the environment by removal of moisture by precipitation, raising the cloud-base level and the CIN. A stronger wind shear means more tilt hence, more separation of downdraft air from updraft inflow so that each cell lasts longer.

Such a role of wind shear in organized convection is implemented into an archetype parameterization developed by Moncrieff $(1981,1992)$. However, some major irony with this parameterization is that it lacks a closure condition. Thus, our theoretical reflections in this section conclude with a caveat that identifying controlling variables for convective intensity, a main persuasion of the present review, is not a sufficient condition for defining a parameterization closure.

\section{Conclusions}

The present paper has reviewed the closure of convection parameterization from phenomenological perspectives. Loosely speaking, the closure refers to the problem of defining a convective intensity under a convection parameterization. The review has begun by considering global and regional contexts for atmospheric convection in order to set a scene. Regional differences in factors that are contributing in defining the convective intensity are discussed, suggesting that the convective intensity depends on low-to-middle troposphere moisture when CAPE is small, and become relatively insensitive to this moisture when CAPE variation is large.

By following the preview of Sect. 2, we have in Sect. 3.1 more systematically listed physical variables that are expected to contribute in determining the convective intensity. One may wish that a closure formula can be developed by combining all these variables under, e.g., a certain statistical method. However, as it turns out, though it is easy to prepare such a list based on physical reasonings, objective statistical analyses, mostly focused on the tropics, tend to suggest that most of them do not contribute significantly to defining the convective intensity or whether a convective event happens or not.

The most disappointing of such conclusions come for both CAPE and CIN. Those two major variables, which are commonly considered as controlling convection, do not present statistical significance. On the other hand, in spite of a secondary role from a point of view of energetics of convection, the water vapor tends to stand out in observational correlation analysis.

Here, problems associated with this type of observational diagnostic studies must be recognized. Most fundamentally, this type of study is incapable of telling anything about causality. The most practical problem is a difficulty in identifying "convection" itself objectively from conventional observations. For this reason, in most of the above studies, the convective intensity is measured by the precipitation rate. Though this may be a valid assumption over the tropics, use of the precipitation rate over the midlatitudes as a measure of convection is highly questionable, where the precipitation is dominated by the synoptic-scale processes. Identification of the convection controlling parameter observationally over the midlatitudes remains a major challenge.

Moreover, a diagnostically obtained relationship does not necessarily present a useful closure relationship. A good example comes from the scalings developed by Shutts and Gray (1999) for a set of equilibrium convection simulations. Combining their Eqs. (8) and (15) gives a relation for the cloudbase mass flux, $M_{\mathrm{B}}$, as being proportional to $F_{h} / \mathrm{CAPE}$, where $F_{\mathrm{h}}$ is the surface moist static energy flux. The relation provides a good estimate for CAPE if the mass flux is known (Shutts and Gray, 1999), but is too unstable to be used in the 
reverse sense to predict the mass flux as a practical closure condition (R. S. Plant, personal communication, 2012). Consider a small perturbation that leads to a slight excess of mass flux relative to the value required for equilibrium. The excess mass flux reduces the CAPE and so gives rise to a positive feedback that further increases the closure mass flux.

In face of difficulties in defining a closure based on a statistical data analysis, an alternative possibility of inferring a preferred closure formulation based on stability analyses of tropical convectively coupled waves is sought. The theoretically obtained stability characteristics of the waves must be consistent with observations if the given closure hypothesis is physically based. A particular series of works reviewed here again favors the water-vapor closure over the CAPE closure. However, we should not take it as a final word from the linear stability analysis. Especially, the consistency between a parameterization formulation adopted under the stability analysis and that in operational models must carefully be scrutinized.

Various theoretical reflections are presented from various different points of views. In operational implementations (P. Bechtold, personal communication, 2012), there are difficulties of making a moisture closure work, although we should not take it as a final verdict on this closure. From a point of view that convection is a dynamical process, it is more natural to base the closure on an energy cycle of convection. CAPE is a standard choice for this purpose.

Here, two caveats may be emphasized: as discussed in Sect. 5.4, the observations prove that one cannot use CAPE closures in the manner that has been used in the past. Rather, we must either follow parcel-environment contribution to CAPE change or treat the subgrid-scale variability of CAPE. Furthermore, as emphasized in Sect. 5.6, we need to move to more explicit treatments of the cloud work function. Once an exponential power, $p$, in Eq. (4) is specified, the convective energy cycle based on the cloud work function provides a more consistent description of the evolution of convective ensembles than any alternative closures currently available.

We emphasize various important background issues to be considered in order to deal with the convectionparameterization closure problem under a solid basis. However, unfortunately, the present review tends to point to difficulties of putting the operational experiences in both theoretical and observational contexts. Difficulties are further compounded by the fact that these operational experiences are not well documented in the literature. Though parameterization comparison studies are abundant (e.g., Wang and Seaman, 1997), they often fail to pinpoint the issues behind the closures.

There is still a long list of issues to be resolved concerning the convection-parameterization closure. A particular example is the issues of the high-resolution limit. More generally, the scale dependence of the closure is still a wide open question. This issue is only briefly discussed in considering the PBL-based closure in the present review. A ma- jor remaining challenge is to develop both theoretical and observational studies that can positively contribute to the parameterization closure problem in operational contexts. The goal of the current COST Action ES0905 (2010-2014: http://convection.zmaw.de) is to develop a common ground for theoretical, observational, and operational researchers for identifying a much needed breakthrough.

Acknowledgements. The present manuscript is an outcome of discussions over e-mail organized under a framework of COST Action ES0905. Along with the authors, Elisabetta Fiori, JeanFrancois Geleyn, Peter Bechtold, Robert S. Plant, Johannes Quaas, Sandra Turner, Till Wagner participated in the discussion. P. Bechtold and R. S. Plant have also contributed specific remarks for the text.

Edited by: J. Quaas

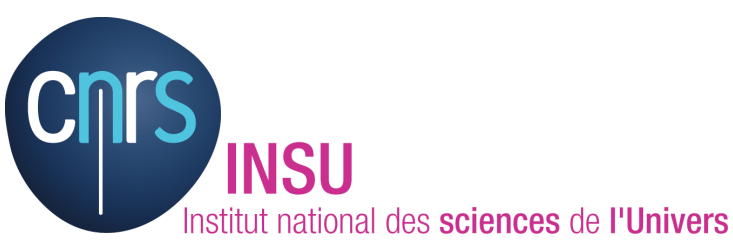

The publication of this article is financed by CNRS-INSU.

\section{References}

Arakawa, A.: Closure assumptions in the cumulus parameterization problem, in: The Representation of Cumulus Convection in Numerical Models, Meteor. Mono., No. 46, Amer. Meteor. Soc., 115, 1993.

Arakawa, A.: The cumulus parameterization problem: past, present, and future, J. Climate, 17, 2493-2525, 2004.

Arakawa, A. and Chen, J.-M.: Closure assumptions in the cumulus parameterization problem, in: Short- and Medium-Range Numerical Weather Prediction, Collection of Papers at the WMO/IUGG NWP Symposium, Tokyo, 4-8 August 1986, 107131, 1986.

Arakawa, A. and Schubert, W. H.: Interaction of a cumulus cloud ensemble with the large-scale environment, pt. I, J. Atmos. Sci., 31, 674-701, 1974.

Back, L. E. and Bretherton, C. S.: Geographic variability in the export of moist static energy and vertical motion profiles in the Tropical Pacific, Geophy. Res. Lett., 33, L17810, doi:10.1029/2006GL026672, 2006

Barkidija, S. and Fuchs, Ž.: Precipitation correlation between convective available potential energy, convective inhibition and saturation fraction in middle latitudes, Atmos. Res., 124, 170-180, 2013.

Bechtold, P., Bazile, E., Guichard, F., Mascart, P., and Richard, E.: A mass-flux convection scheme for regional and global models, Q. J. Roy. Meteorol. Soc., 127, 869-889, 2001.

Betts, A. K. and Silva Dias, M. F.: Unsaturated downdraft thermodynamics in cumulonimbus. J. Atmos. Sci., 36, 1979, 1061$1071,1979$. 
Bister, M.: Cumulus Parameterisation in Regional Forecast Models: a Review, Hirlam Technical Report, No. 35, 1998.

Bretherton, C. S. and Wyant, M. C.: Moisture transport, lower stratospheric stability, and decoupling of cloud-topped boundary layers, J. Atmos. Sci., 54, 148-167, 1997.

Bretherton, C. S., McCaa, J. R., and Grenier, H.: A new parameterization for shallow cumulus convection and its application to marine subtropical cloud-topped boundary layers. Part I: Description and 1D results, Mon. Weather Rev., 132, 864-882, 2004.

Bretherton, C. S., Blossey, P. N., Khairoutdinov, M.: An energybalance analysis of deep convective self-aggregation above uniform SST, J. Atmos. Sci., 62, 4273-4292, 2005.

Brown, R. G. and Zhang, C.: Variability of midtropospheric moisture and its effect on cloud-top height distribution during TOAG COARE, J. Atmos. Sci., 54, 2760-2774, 1997.

Chaboureau, J.-P., Guichard, F., Redelsperger, J.-L., and Lafore, J.P.: The role of stability and moisture in the diurnal cycle of convection over land, Q. J. Roy. Meteorol. Soc., 130, 3105-3117, 2004.

Charney, J. G. and Eliassen, A.: On the growth of the hurricane depression, J. Atmos. Sci., 21, 68-75, 1964.

Cho, H.-R. and Kenkins, M. A.: The thermal structure of tropical easterly waves. J. Atmos. Sic., 44, 2531-2539, 1987.

Delayen, K. and Yano, J.-I.: Is asymptotic nondivergence of the large-scale tropical atmosphere consistent with equatorial wave theories?, Tellus, 61A 491-497, 2009.

Derbyshire, S. H., Beau, I., Bechtold, P., Grandpeix, J.-Y., Piriou, J.M., Redelsperger, J.-L., and Soares, P. M. M.: Sensitivity of moist convection to environmental humidity, Q. J. Roy. Meteorol. Soc., 130, 3055-3079, 2004.

Derbyshire, S. H., Maidens, A. V., Milton, S. F., Stratton, R. A., and Miller, M. R.: Adaptive detrainment in a convective parameterization, Q. J. Roy. Meteorol. Soc., 137, 1856-1871, 2011.

de Rooy, W. C., Bechtold, P., Fröhlich, K., Hohenegger, C., Jonker, H., Mironov, D., Siebesma, A. P., Teixeira, J., Yano, J.-I.: Entrainment and detrainment in cumulus convection: an overview, Q. J. Roy. Meteorol. Soc., 139, 1-19, doi:10.1002/qj.1959, 2013.

Donner, L. J.: A cumulus parameterization including mass fluxes, vertical momentum dynamics, and mesoscale effects, J. Atmos. Sci., 50, 889-906, 1993.

Donner, L. J. and Phillips, V. T.: Boundary layer control on convective available potential energy: implications for cumulus parameterization, J. Geophys. Res., 108, 4701, doi:10.1029/2003JD003773, 2003.

Emanuel, K. A.: An air-sea interaction model of intraseasonal oscillations in the tropics, J. Atmos. Sci., 44, 2324-2340, 1987.

Emanuel, K. A.: Atmospheric Convection, Oxford University Press, 580 pp., 1994.

Emanuel, K. A. and Bister, M.: Moist convective velocity and buoyancy scales, J. Atmos. Sci., 53, 3276-3285, 1996.

Emanuel, K. A., Neelin, J. D., and Bretherton, C. S.: On large-scale circulation in convective atmospheres, Q. J. Roy. Meteorol. Soc., 120, 1111-1143, 1994.

Fuchs, Ž.: Large-scale modes of the tropical atmosphere. Part II: analytical modeling of Kelvin waves using the CAPE closure, Geofizika, 24, 44-55, 2007.

Fuchs, Ž. and Raymond, D. J.: Large-scale modes of a nonrotating atmosphere with water vapor and cloud-radiative feedbacks,
J. Atmos. Sci., 59, 1669-1679, 2002.

Fuchs, Ž. and Raymond, D. J.: Large-scale modes in a rotating atmosphere with radiative-convective instability and WISHE, J. Atmos. Sci., 62, 4084-4094, 2005.

Fuchs, Ž. and Raymond, D. J.: A simple, vertically resolved model of tropical disturbances with a humidity closure, Tellus, 59A, 344-354, 2007.

Fuchs, Ž., Gjorgjievska, S., and Raymond, D. J.: Effects of varying the shape of the convective heating profile on convectively coupled gravity waves and moisture modes. J. Atmos. Sci., 69, 2505-2519, 2012.

Gerard, L.: An integrated package for subgrid convection, clouds and precipitation compatible with the meso-gamma scales. Quart. J. Roy. Meteor. Soc., 133, 711-30, 2007;

Gerard, L. and Geleyn, J.-F.: Evolution of a subgrid deep convection parameterization in a limited-area model with increasing resolution, Quart. J. Roy.Meteor. Soc., 131, 2293-2312, 2005.

Gerard, L., Piriou, J.-M., Brožková, R., Geleyn, J.-F. and Banciu, D.: Cloud and precipitation parameterization in a mesogamma-scale operational weather prediction model, Mon. Weather Rev., 137, 3960-3977, 2009.

Grandpeix, J.-Y. and Lafore, J.-P.: A Density Current Parameterization Coupled with Emanuel's Convection Scheme. Part I: The Models, J. Atmos. Sci., 67, 881-897, 2010.

Hayashi, Y.: A theory of large-scale equatorial waves generated by condensation heat and accelerating the zonal wind, J. Meteor. Soc. Jpn., 48, 140-160, 1970.

Hayashi, Y.: Large-scale equatorial waves destabilized by convective heating in the presence of surface friction, J. Meteor. Soc. Jpn., 49, 458-466, 1971.

Hohenegger, C. and Bretherton, C. S.: Simulating deep convection with a shallow convection scheme, Atmos. Chem. Phys., 11, 10389-10406, doi:10.5194/acp-11-10389-2011, 2011.

Hourdin, F, Grandpeix, J.-Y., Rio, C., Bony, S., Jam, A., Cheruy, F., Rochetin, N., Fairhead, L., Idelkadi, A., Musat, I., Dufresne, J.L., Lefebvre, M.-P., Lahellec, A., and Roehrig, R.: From IPSL-CM5A to IPSL-CM5B: revisiting the parameterization of boundary-layer, clouds and convection in the LMDZ atmospheric model, Clim Dyn., doi:10.1007/s00382-012-1343-y, 2012.

James, R. P. and Markowski, P. M.: A numerical investigation of the effects of dry air aloft on deep convection, Mon. Weather Rev., 138, 140-161, 2010.

Kain, J. S.: The Kain-Fritsch convective parameterization: an update, J. Appl. Meteor., 43, 170-181, 2004.

Khairoutdinov, M. and Randall, D.: High-resolution simulation of shallow-to-deep convection transition over land, J. Atmos. Sci., 63, 3421-3436, 2006.

Kiladis, G. N., Straub, K. H., and Haertel, P. T.: Zonal and vertical structure of the Madden-Julian oscillation, J. Atmos. Sci., 62, 2790-2809, 2005.

Kiladis, G. N., Wheeler, M. C., Haertel, P. T., Straub, K. H., and Roundy, P. E.: Convectively coupled equatorial waves, Rev. Geophy., 472, RG2003, doi:10.1029/2008RG000266, 2009.

Klemp, J. B.: Dynamics of tornadic thunderstorms, Ann. Rev. Fluid Mech., 19, 369-402, 1987.

Kuell, V., Gassmann, A., and Bott, A.: Towards a new hybrid cumulus parametrization scheme for use in non-hydrostatic weather prediction models, Quart. J. Roy. Meteor. Soc., 133, 479-490, 2007. 
Kuo, H. L.: Further studies of the parameterization of the influence of cumulus convection on large-scale flow, J. Atmos. Sci., 31, 1232-1240, 1974.

Lilly, D. K.: Model of cloud-topped mixed layers under a strong inversion, Q. J. Roy. Meteorol. Soc., 94, 292-309, 1968.

Lindzen, R.: Wave-CISK in the tropics, J. Atmos. Sci., 31, 156-179, 1974.

Lorenz, E. N.: Available energy and the maintenance of a moist circulation, Tellus, 30, 15-31, 1978.

Lorenz, E. N.: Numerical evaluation of moist available energy, Tellus, 31, 230-235, 1979.

Majda, A. J. and Shefter, M. G.: Models for stratiform instability and convectively coupled waves, J. Atmos. Sci., 58, 1567-1584, 2001

Mapes, B. E.: Equilibrium vs. activation controls on large-scale variations of tropical deep convection, in: The Physics and Parameterization of Moist Atmospheric Convection, edited by: Smith, R. K., NATO ASI, Kloster Seeon, Kluwer Academic Publishers, Dordrecht, 321-358, 1997.

Mapes, B. E.: The large-scale part of mesoscale convective system circulations: a linear vertical spectral band model, J. Meteor. Soc. Jpn., 76, 29-55, 1998.

Mapes, B. E.: Convective inhibition, subgrid-scale triggering energy, and stratiform instability in a toy tropical wave model, J. Atmos. Sci., 57, 1515-1535, 2000.

Mapes, B. E., Tulich, S., Lin, J.-L., and Zuidema, P.: The mesoscale convection life cycle: building block or prototype for large-scale tropical waves?, Dynam. Atmos. Oceans, 42, 3-29, 2006.

Mapes, B. E., Milliff, R., and Morzel, J.: Composite life cycle of maritime tropical mesoscale convective systems in scatterometer and microwave satellite observations, J. Atmos. Sci., 66, 199208, 2009.

McBride, J. L. and Frank, W. M.: Relationships between stability and monsoon convection, J. Atmos. Sci., 56, 24-36, 1999.

Moncrieff, M. W.: A theory of organized steady convection and its transport properties, Q. J. Roy. Meteor. Soc., 107, 29-50, 1981.

Moncrieff, M. W.: Organized convective systems: archetypal dynamical models, mass and momentum flux theory, and parametrization, Q. J. Roy. Meteor. Soc., 118, 819-850, 1992.

Moncrieff, M. W. and Green, J. S. A.: The propagation and transfer properties of steady convective overturning in shear, Q. J. Roy. Meteorol. Soc., 98, 336-352, 1972.

Moncrieff, M. W. and Miller, M. J.: The dynamics and simulation of tropical cumulonimbus and squall lines, Q. J. Roy. Meteorol. Soc., 102, 373-394, 1976.

Neelin, J. D. and Held, I. M.: Modeling tropical convergence based on the moist static energy budget, Mon. Weather Rev., 115, 3-12, 1987.

Neelin, J. D. and Yu, J.-Y.: Modes of tropical variability under convective adjustment and the Madden-Julian oscillation. Part I: Analytical theory, J. Atmos. Sci., 51, 25-42, 1994.

Neelin, J. D., Held, I. M., and Cook, K. H.: Evaporation-wind feedback and low-frequency variability in the tropical atmosphere, J. Atmos. Sci., 44, 2341-2348, 1987.

Newell, R. E., Kidson, J. W., Vincent, D. G., and Boer, G. J.: The General Circulation of the Tropical Atmosphere, Vol. 2, The MIT Press, 1974.

Ooyama, K. V.: Conceptual evolution of the theory and modeling of the tropical cyclone, J. Meteor. Soc. Jpn., 60, 369-380, 1982.
Pan, D.-M. and Randall, D. A.: A cumulus parameterization with prognostic closure, Q. J. Roy. Meteorol. Soc., 124, 949-981, 1998.

Parodi, A. and Emanuel, K.: A theory for buoyancy and velocity scales in deep moist convection, J. Atmos. Sci., 66, 3449-3463, 2009.

Paulus, O.: Water vapor and mechanical work: A comparison of Carnot and stream cycles, J. Atmos. Sci., 68, 91-012, 2011.

Peters, O. and Neelin, D.: Critical phenomena in atmoshperic precipitation, Nat. Phys., 2, 393-396, doi:10.1038/Nphys314, 2006.

Randall, D. A. and Pan, D.-M.: Implementation of the ArakawaSchubert cumulus parameterization with a prognostic closure, in: The Representation of Cumulus Convection in Numerical Models, Meteorological Monographs No. 46, edited by: Emanuel, K. A. and Raymond, D. J., Amer. Meteor. Soc., 137144, 1993.

Randall, D. A. and Wang, J.: The moist available energy of a conditionally unstable atmosphere, J. Atmos. Sci., 49, 240-255, 1992.

Raymond, D. J.: Regulation of moist convection over the warm tropical oceans, J. Atmos. Sci., 52, 3945-3959, 1995.

Raymond, D. J.: Thermodynamic control of tropical rainfall, Q. J. Roy. Meteorol. Soc., 126, 889-898, 2000.

Raymond, D. J. and Fuchs, Ž.: Convectively coupled gravity and moisture modes in a simple atmospheric model, Tellus, 59A 627640, 2007.

Raymond, D. J. and Fuchs, Ž.: Moisture modes and the MaddenJulian oscillation, J. Climate, 22, 3031-3046, 2009.

Raymond, D. J. and Herman, M. J.: Convective quasi-equilibrium reconsidered, J. Adv. Model. Earth Syst., 3, 2011MS000079, doi:10.1029/2011MS000079, 2011.

Raymond, D. J., Raga, G. B., Bretherton, C. S., Molinari, J., LópezCarrillo, C., and Fuchs, Ž.: Convective forcing in the intertropical convergence zone of the Eastern Pacific, J. Atmos. Sci., 60, 2064-2082, 2003.

Raymond, D. J., Sessions, S. L., and Fuchs, Ž.: A theory for the spinup of tropical depressions, Q. J. Roy. Meteorol. Soc., 133, 1743-1754, 2007.

Raymond, D. J., Sessions, S. L., Sobel, A. H., and Fuchs, Ž.: The mechanism of gross moist stability, J. Adv. Model. Earth Syst., 1, 9, doi:10.3894/JAMES.2009.1.9, 2010.

Ramage, C. S.: Monsoon Meteorology, Academic Press, New York, 296 pp., 1971.

Redelsperger, J.-L., Parsons, D. B., and Guichard, F.: Recovery processes and factors limiting cloud-top height following the arrival of a dry intrusion observed during TOGA-COARE, J. Atmos. Sci., 59, 2438-2457, 2002.

Reed, R. J., and Recker, E. E.: Structure and properties of synopticscale wave disturbances in the equatorial western Pacific, J. Atmos. Sci., 28, 1117-1133, 1971.

Reed, R. J., Norquiest, D. C., and Recker, E. E.: The structure and properties of African waves disturbances as observed during Phase III of GATE, Mon. Wea. Rec., 105, 317-333, 1977.

Rennó, N. O. and Ingersoll, A. P.: Natural convection as a heat engine: a theory for CAPE, J. Atmos. Sci., 53, 572-585, 1996.

Rio, C., Hourdin, F., Grandpeix, J.-Y., and Lafore, J.-P.: Shifting the diurnal cycle of parameterized deep convection over land, Geophys. Res. Lett., 36, L07809, doi:10.1029/2008GL036779, 2009. 
Rio, C., Hourdin, F., Grandpeix, J.-Y., Hourdin, H., Guichard, F., Couvreux, F., Lafore, J.-P., Fridlind, A., Mrowiec, A., Roehrig, R., Rochetin, N., Lefebvre, M.-P., and Idelkadi, A.: Control of deep convection by sub-cloud lifting processes: the ALP closure in the LMDD5B general circulation model, Clim. Dyn., doi:10.1007/s00382-012-1506-x, 2012.

Rotunno, R., Klemp, J. B., and Weisman, M. L.: A theory for strong, long-lived squall lines, J. Atmos. Sci., 45, 463-485, 1988.

Schubert, W. H., Wakefield, J. S., Steiner, E. J., and Cos, S. K.: Marine stratocumulus convection, Part I: Governing equations and horizontally homogeneous solutions, J. Atmos. Sci., 36, 12861307, 1979.

Sherwood, S. C.: Convective precursors and predictability in the Tropical Western Pacific, Mon. Weather Rev., 127, 2977-2991, 1999.

Sherwood, S. C. and Wahrlich, R.: Observed evolution of tropical deep convection event and their environment, Mon. Weather Rev., 127, 1777-1795, 1999.

Shutts, G. J. and Gray, M. E. B.: Numerical simulations of convective equilibrium under prescribed forcing, Q. J. Roy. Meteorol. Soc., 125, 2767-2787, 1999.

Sobel, A. H., Nilsson, J., and Polvani, L. M.: The weak temperature gradient approximation and balanced tropical moisture waves, J. Atmos. Sci., 58, 3650-3665, 2001.

Sobel, A. H., Yuter, S. E., Bretherton, C. S., and Kiladis, G. N.: Large-scale meteorology of shallow cumulus convection, J. Atmos. Sci., 60, 1201-1219, 2004.

Stone, P. H. and Carlson, J. H.: Atmospheric lapse rate regimes and their parameterization, J. Atmos. Sci., 36, 415-423, 1979.

Stensrud, D. J.: Parameterization schemes, Cambridge University Press, 459 pp., 2007.

Sugiyama, M.: The moistue mode in the quasi-equilibrium tropical model. Part I: Analysis based on the weka tempeature gradient approximation, J. Atmos. Sic., 66, 1507-1523, 2009a.

Sugiyama, M.: The moistue mode in the quasi-equilibrium tropical model. Part II: Nonlinear behavior on an equatorial $\beta$-plane. J. Atmos. Sci., 66, 1525-1542, 2009b.

Thompson, R. M., Payne, S. W., Recker, E. E., and Reed, R. J.: Structure and properties of synoptic-scale wave disturbances in the intertropical convergence zone of the Eastern Atlantic, J. Atmos. Sci., 36, 53-72, 1979.

Thorpe, A. J., Miller, M. J., and Moncrieff, M. W.: Two-dimensional onvection in non-constant shear: a model of mid-latitude squall lines, Q. J. Roy. Meteor. Soc., 108, 739-762, 1982.

$\mathrm{Xu}, \mathrm{K} . \mathrm{M}$.: A statistical analysis of the dependency of closure assumptions in cumulus parameterization on the horizontal resolution, J. Atmos. Sci., 51, 3674-3691, 1994.

$\mathrm{Xu}, \mathrm{K} . \mathrm{M}$. and Randall, D. A.: Influence of large-scale advedctive cooling and moisture effects on the quasi-equilibrium behavior of explicitly simulated cumulus ensembles, J. Atmos. Sci., 55, 896-909, 1998.

Wang, J. and Randall, D. A.: The moist available energy of a conditionally unstable atmosphere, Part II: Further analysis of GATE data, J. Atmos. Sci., 51, 703-710, 1994.

Wang, W. and Seaman, N. L.: A comparison study of convective parameterization schemes in a mesoscale model, Mon. Weather Rev., 125, 252-278, 1997.

Weisman, M. L. and Klemp, J. B.: The dependence of numerically simulated convective storms on vertical wind shear and buoy- ancy, Mon. Weather Rev., 110, 504-520, 1982.

Wu, C. M., Stevens, B., and Arakawa, A.: What controls the transition from shallow to deep convection?, J. Atmos. Sci., 66, 17931806, 2008.

Yano, J.-I.: The cumulus parameterization problem in the context of MJO simulations, Proceedings for the MJO workshop, ECMWF, 2-5 November 2003, 115-127, 2003.

Yano, J.-I.: Interactive comment on "Simulating deep convection with a shallow convection scheme" by Hohenegger, C., and Bretherton, C. S., On PBL-based closure, Atmos. Chem. Phys. Discuss., 11, C2411-C2425, http://www. atmos-chem-phys-discuss.net/11/C2411/2011/, 2011.

Yano, J.-I.: Comments on "A Density Current Parameterization Coupled with Emanuel's Convection Scheme. Part I: The Models", J. Atmos. Sci., 69, 2083-2089, 2012a.

Yano, J.-I.: Mass-flux subgrid-scale parameterization in analogy with multi-component flows: a formulation towards scale independence, Geosci. Model Dev., 5, 1425-1440, doi:10.5194/gmd5-1425-2012, 2012b.

Yano, J.-I. and Baizig, H.,: Single SCA-Plume Dynamics, Dyn. Atmos. Ocean., 58, 62-94, 2012.

Yano, J.-I. and Bonazzola, M.: Scale analysis for the large-scale tropical atmospheric dynamics, J. Atmos. Sci., 66, 159-172, 2009.

Yano, J. I. and Emanuel, K. A.: An improved model of the equatorial troposphere and its coupling with the stratosphere, J. Atmos. Sci., 48, 377-389, 1991.

Yano, J.-I. and Plant, R. S.: Convective quasi-equilibrium, Rev. Geophys., 50, RG4004, doi:10.1029/2011RG000378, 2012a.

Yano, J.-I. and Plant, R. S.: Finite departure from convective quasi-equilibrium: periodic cycle and discharge-recharge mechanism, Q. J. Roy. Meteor. Soc., 138, 626-637, doi:10.1002/qj.957, 2012b.

Yano, J.-I. and Plant, R. S.: Interactions between shallow and deep convection under a finite departure from convective quasiequilibrium, J. Atmos. Sci., 69, 3463-3470, doi:10.1175/JAS-D12-0108.1, 2012c

Yano, J.-I., Moncrieff, M. W., and McWilliams, J. C.: Linear stability and single-column analyses of several cumulus parameterization categories in a shallow-water model, Q. J. Roy. Meteorol. Soc., 124, 983-1005, 1998.

Yano, J.-I., Grabowski, W. W., Roff, G. L., and Mapes, B. E.: Asymptotic approaches to convective quasi-equilibrium, Q. J. Roy. Meteorol. Soc., 126, 1861-1887, 2000.

Yano, J.-I., Blender, R., Zhang, C., and Fraedrich, K.: 1/ $f$-noise and pulse-like events in the tropical atmospheric surface variabilities, Quator. J. Roy. Meteor. Soc., 300, 1697-1721, 2004.

Yano, J.-I., Redelsperger, J.-L., Guichard, F., and Bechtold, P.: Mode decomposition as a methodology for developing convective-scale representations in global models, Q. J. Roy. Meteorol. Soc., 131, 2313-2336, 2005a.

Yano, J.-I., Chaboureau, J.-P., and Guichard, F.: A generalization of CAPE into potential-energy convertibility, Q. J. Roy. Meteorol. Soc., 131, 861-875, 2005b.

Yano, J.-I., Mulet, S., and Bonazzola, M.: Large-scale tropical atmosphere: asymptotically non-divergent?, Tellus, 61A, 417-427, 2009.

Yano, J.-I., Liu, C., and Moncrieff, M. W.: Self-criticality and homeostasis in atmospheric convective organization, J. Atmos. Sci., 
69, 3449-3462, doi:10.1175/JAS-D-12-069.1, 2012.

Zhang, G. J.: Convective quasi-equilibrium in midlatitude continental environment and its effect on convective parameterization, J. Geophys. Res., 107, 4220, doi:10.1029/2001JD001005, 2002.
Zhang, Y. and Klein, S. A.: Mechanism affecting the transition from shallow to deep convection over land: inferences form observations of the diurnal cycle collected at the ARM Southern Great Plains site, J. Atmos. Sci., 67, 2943-2959, 2010. 